\title{
Thermal-Sprayed Photocatalytic Coatings for Biocidal Applications: A Review
}

\author{
Yi Liu ${ }^{1,2} \cdot$ Jing Huang ${ }^{1,2} \cdot$ Xiaohua Feng ${ }^{1,2} \cdot \mathrm{Hua} \mathrm{Li}^{1,2}$
}

Submitted: 24 August 2020/in revised form: 5 October 2020/Published online: 4 November 2020

(c) ASM International 2020

\begin{abstract}
There have been ever-growing demands for disinfection of water and air in recent years. Efficient, ecofriendly, and cost-effective methods of disinfection for pathogens are vital to the health of human beings. The photocatalysis route has attracted worldwide attention due to its highly efficient oxidative capabilities and sustainable recycling, which can be used to realize the disinfection purposes without secondary pollution. Though many studies have comprehensively reviewed the work about photocatalytic disinfection, including design and fabrication of photocatalytic coatings, inactivation mechanisms, or practical applications, systematic reviews about the disinfection photocatalysis coatings from fabrication to effort for practical use are still rare. Among different ways of fabricating photocatalytic materials, thermal spray is a versatile surface coating technique and competitive in constructing large-scale functional coatings, which is a
\end{abstract}

This article is an invited paper selected from invited presentations at the International Thermal Spray Conference 2021 Virtual Preview Session on Coatings for Anti-Virus, Bacteria, and Fungus Applications, held on June 18, 2020, and has been expanded from the original oral presentation.

Yi Liu

liuyi@nimte.ac.cn

$凶$ Hua Li

lihua@nimte.ac.cn

$1 \quad$ Key Laboratory of Marine Materials and Related Technologies, Ningbo Institute of Materials Technology and Engineering, Chinese Academy of Sciences, Ningbo 315201, China

2 Zhejiang Engineering Research Center for Biomedical Materials, Cixi Institute of Biomedical Engineering, Ningbo Institute of Materials Technology and Engineering, Chinese Academy of Sciences, Ningbo 315201, China most promising way for the future environmental purification, biomedical and life health applications. In this review, we briefly introduced various photocatalytic materials and corresponding inactivation mechanisms for virus, bacteria and fungus. We summarized the thermalsprayed photocatalysts and their antimicrobial performances. Finally, we discussed the future perspectives of the photocatalytic disinfection coatings for potential applications. This review would shed light on the development and implementation of sustainable disinfection strategies that is applicable for extensive use for controlling pathogens in the near future.

Keywords coating $\cdot$ disinfection $\cdot$ inactivation mechanisms · photocatalyst - thermal spray

\section{Introduction}

A variety of pathogens (e.g., bacteria, viruses, fungi, algae) exist in water and air (Ref 1-4). Owing to the health threat caused by infections through air, water, food and a range of other modes of infection, elimination of the pathogens is a significant concern, which leads to a growing demand for disinfection techniques (Ref 5-7). Numerous measures have been taken to tackle the microbial contamination problems, among which the conventional methods were usually based on physical and biological strategies, including conventional chemical disinfectants (e.g., chlorine, chlorine dioxide, ozone, and alcohol, formaldehyde, or hydrogen peroxide), antimicrobial drugs (e.g., antibiotics) and ultraviolet irradiation (UV-C, UV-B and UV-A) (Ref 8-11). However, the chemical disinfectants or antimicrobial drugs usually brought about other concerns including secondary toxic pollutants, drug resistance, and 
extra consumption (resources/energy used in producing the chemicals), while the methods using UV-induced processes have also been found to suffer from a lack of residual effect. Therefore, new disinfection techniques have been developed to address the shortcomings of the conventional methods.

Advanced oxidation processes (AOPs), including photocatalysis, offer good potential alternative for disinfection purpose without extra consumption or producing secondary pollutants. As one of the AOPs method, photocatalysis route is regarded as a most promising antimicrobial strategy. In the process of eliminating pathogens in air, water, or on solid surface, the photocatalyst can be excited by light irradiation to produce $\mathrm{h}^{+}$and a series of powerful reactive oxide species (ROSs) including $\cdot \mathrm{O}^{2-}, \cdot \mathrm{OH}$, and $\mathrm{H}_{2} \mathrm{O}_{2}$ for inactivation of pathogenic microbes without secondary pollution. There are no mass loss and performance decrease for photocatalytic materials when they perform purification functions. Therefore, photocatalysis route has a number of advantages over the conventional disinfection methods (e.g., chemical disinfectants, UV irradiation, etc.), including good reusability, long-term stability, and eco-friendliness. Since the discovery of the photocatalytic water splitting effect of $\mathrm{TiO}_{2}$ by Fujishima and Honda in 1972, research in photocatalysis has been carried out for the disinfection use, showing great potentials in air treatment, water remediation, food preservation, and many other fields (Ref 12).

Until now, photocatalytic disinfection has become an effective route for inactivation of different pathogens (e.g., bacteria, viruses, or fungi, etc.). Photocatalytic material is a key factor to achieve high effective anti-infection. In the last two decades, ever-growing efforts have been made for the development of photocatalytic disinfection applications. Two categories of photocatalysts have been developed for inactivation of microbial species: the metal oxides like photocatalysts, including $\mathrm{TiO}_{2}$ (Ref 13), zinc oxide $(\mathrm{ZnO})$ (Ref 14), tungsten oxide $\left(\mathrm{WO}_{3}\right)$ (Ref 15), and the nonmetal catalysts, such as graphitic carbon nitride (g$\mathrm{C}_{3} \mathrm{~N}_{4}$ ) (Ref 16), $\mathrm{C}_{60}$ (Ref 17), and so on. With the advance of analytical methods for pathogens detection and increasing public health concern, there is a pressing need to evaluate the performance of photocatalysis as an ecofriendly, cost-effective, and sustainable strategy for the disinfection of air, water, and solid surface and also the future opportunities for industrial use.

Most of the photocatalytic powders and suspensions perform outstanding photocatalytic efficiency in eliminating the waterborne pathogens due to high surface area. However, drawbacks of difficulty in separation and recycling of the photocatalysts in suspension are the major factors that hindered their application in versatile environmental conditions. To tackle the problem, researchers developed different methods to immobilize the photocatalysts onto certain solid substrates or supports, which combines the advantages of functionality and practicability in photocatalytic disinfection. Among different methods of immobilization, surface coating technique is a most promising one in fabricating functional coatings with photocatalytic antimicrobial properties.

Among different synthesis methods of surface coatings, thermal spray technique (e.g., plasma spray, flame spray, high-velocity oxygen-fuel spray, electric arc spraying, and cold spray) offers facile one-step fabrication of large-scale photocatalytic materials on arbitrary solid surfaces and also the capability of mass synthesis of photocatalytic materials via chemical reaction during the spraying processing. Therefore, the thermal spray method has great potentials in fabricating functional photocatalytic coatings with biocidal properties.

In this review, four categories of photocatalytic materials, i.e., $\mathrm{TiO}_{2}$ - and $\mathrm{TiO}_{2}$-based photocatalysts, metalcontaining photocatalysts other than $\mathrm{TiO}_{2}$-based materials, metal-free photocatalysts, and two-dimensional photocatalysts for pathogen inactivation, were introduced. Moreover, we critically reviewed the antimicrobial performance and mechanisms of newly developed thermal-sprayed photocatalytic coatings from different emerging trends in the last two decades. Additionally, we presented the antimicrobial mechanisms of the coatings based on generation of photoactivated reactive oxide species. Finally, we discussed the future challenges and opportunities of thermal-sprayed photocatalytic coatings in disinfection applications.

\section{Typical Photocatalytic Disinfection Materials}

\section{$\mathrm{TiO}_{2}$ - and $\mathrm{TiO}_{2}$-Based Photocatalysts}

$\mathrm{TiO}_{2}$ is one of the most widely studied photocatalysts. $\mathrm{TiO}_{2}$ was extensively explored for photocatalytic disinfection applications over the past years, which shows advantages of high photoactivity and stability, nontoxicity, and low cost. Among different types of $\mathrm{TiO}_{2}$ nanoparticles, Degussa P25 is the most popular photocatalyst, which is widely used for broad spectra anti-bacteria or anti-virus use (Ref 18, 19). Yet two major drawbacks of $\mathrm{TiO}_{2}$ nanomaterials are high recombination rates and large band gap, which limit their photocatalytic disinfection properties. Intensive efforts have been devoted to improving the photocatalytic efficiency of $\mathrm{TiO}_{2}$. One of the most important routes is the modification of $\mathrm{TiO}_{2}$ by using metallic/ nonmetallic elements or metal oxides (Fig. 1) (Ref 20-22). On the one hand, the decoration of $\mathrm{Ag}, \mathrm{CuO}$, or $\mathrm{SiO}_{2}$ nanoparticles was proved to enhance the UV-induced 
Fig. 1 Typical modifications of $\mathrm{TiO}_{2}$ photocatalysts for enhanced disinfection properties (Ref 20)

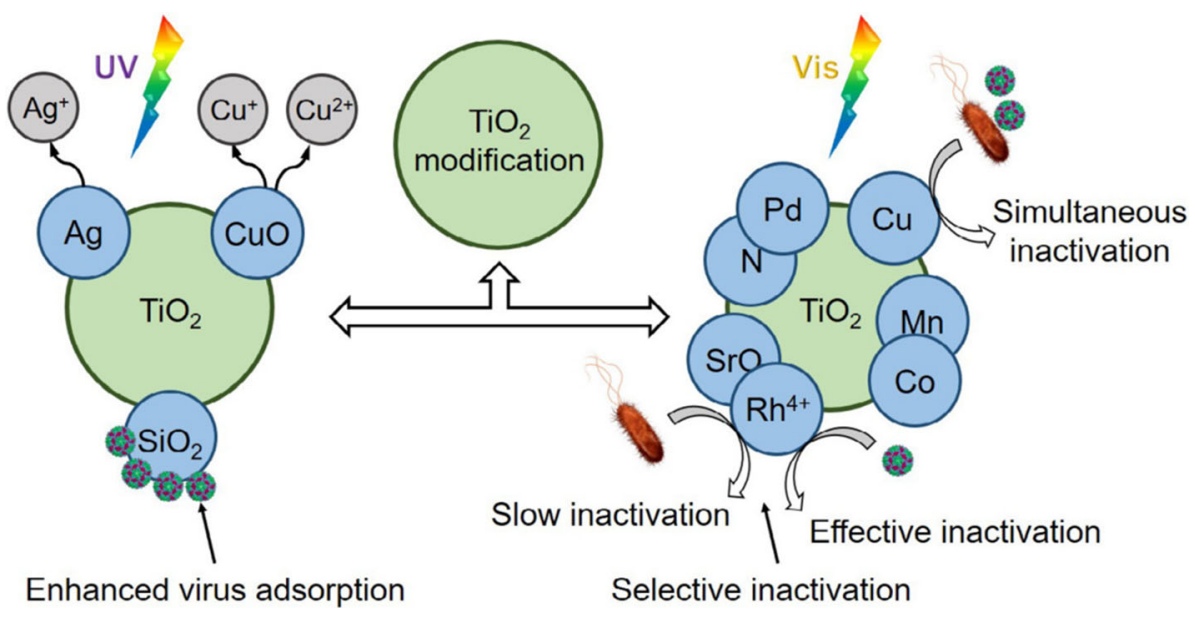

bactericidal effect of $\mathrm{TiO}_{2}$ photocatalysts, among which the $\mathrm{SiO}_{2}$ nanoparticles were also able to enhance the virus adsorption and hence the photocatalytic inactivation efficiency. On the other hand, the decoration of metallic elements (e.g., $\mathrm{Pd}, \mathrm{Cu}, \mathrm{Mn}, \mathrm{Co}$ ), nonmetallic elements (e.g., $\mathrm{N}, \mathrm{F}$ ), or rare earth elements/oxides (e.g., $\mathrm{Rh}^{4+}, \mathrm{SrO}$ ) were also employed to enhance the visible-induced photocatalytic inactivation effect of viruses and bacteria (Ref 2328). Some of the recent work about modifications of $\mathrm{TiO}_{2}$ photocatalysts are summarized as follows.

Precious metals like $\mathrm{Ag}$ and $\mathrm{Cu}$ are commonly used metallic elements for the $\mathrm{TiO}_{2}$ modification. Younas et al. prepared $\mathrm{Ag}$ ion-doped $\mathrm{TiO}_{2}$ nanoparticles by liquid impregnation (LI) method for antibacterial use (Ref 29). The experiments confirmed that under UV light illumination, the particles showed the disinfection efficiency of up to $16 \%$, but when used synergistically with $1 \mathrm{wt} . \% \mathrm{Ag}$ $\mathrm{TiO}_{2}, 100 \%$ of Escherichia coli (E. coli) bacteria were killed in $30 \mathrm{~min} . \mathrm{Cu}$ is an essential trace element in living organisms; thus, it could be used as a $\mathrm{TiO}_{2}$ dopant for visible-light photocatalytic activity but with less toxicity. Gladis et al. reported copper-doped $\mathrm{TiO}_{2}$ nanoparticles synthesized by a two-step method. The sol-gel deposition was followed by microwave hydrothermal treatment, which achieved a band gap reduction down to $2.86 \mathrm{eV}$ at a relatively low nominal doping level of $2.0 \%$ (Ref 30). Remarkable antibacterial properties against both gramnegative and gram-positive bacteria were realized by $\mathrm{TiO}_{2}-$ $\mathrm{Cu}^{2+}$ without any cytotoxicity to human blood cells, which was considered to be related to the leach of $\mathrm{Cu}$ ions in combination with the oxidative attack based on $\mathrm{TiO}_{2}$ photocatalysis.

Since most metallic dopants have toxic effects, nonmetallic elements (e.g., $\mathrm{N}, \mathrm{F}$ ), nano carbon or $\mathrm{SiO}_{2}$ can be used as alternatives for modifying $\mathrm{TiO}_{2}$. By using the nonmetallic dopant, diminished toxicity and improved photocatalytic activity has been seen for the modified catalyst. Janpetch et al. developed a hybrid nanocomposite material of bacterial cellulose (BC) nanofibers and $\mathrm{TiO}_{2}$ nanoparticles, and doping of the material by nitrogen $(\mathrm{N})$ and fluorine $(\mathrm{F})$ gave rise to remarkably enhanced visible-light sensitivity (Ref 31 ). The results showed that $\mathrm{N}-\mathrm{F}$ co-doped $\mathrm{TiO}_{2}$ demonstrated high efficiency of photocatalytic disinfection activity against both gram-negative and gram-positive bacteria under fluorescence light. Metal and nonmetal co-doping techniques were also used to improve the photocatalytic activity of $\mathrm{TiO}_{2}$. For instance, $\mathrm{N}, \mathrm{W}$ co-doping was used to narrow the band gap of $\mathrm{TiO}_{2}$ to about $2.3 \mathrm{eV}$ and achieve high photocatalytic activity under both UV and visible-light illumination (Ref 32).

As to carbon-modified $\mathrm{TiO}_{2}$ photocatalysts, Leary and Westwood proposed several fundamental factors accounting for the enhanced photocatalytic efficiency of $\mathrm{TiO}_{2}$ by incorporating carbonaceous nanomaterials, where decreased band gap, reduced charge-carrier recombination rate, and promoted adsorption of reactants on the photocatalyst surface play the predominate roles (Ref 33). Different kinds of allotropies of carbon were used for the modification of $\mathrm{TiO}_{2}$. Magnetic carbon nanotube (MCNT) composites with titanium dioxide $\left(\mathrm{TiO}_{2}\right)$ have enhanced photocatalytic disinfection efficiency and better applicability than bare $\mathrm{TiO}_{2}$ and/or MCNT, including better solar light applicability and easier catalyst separation process by utilizing its magnetic property. Y. Shimizu et al. investigated the bactericidal mechanism of $E$. coli by using $\mathrm{MCNT}^{-\mathrm{TiO}_{2}}$ nanocomposites under various conditions and photocatalytic disinfection models (Ref 26). The results showed that the MCNT- $\mathrm{TiO}_{2}$ composite had higher disinfection efficiencies than bare $\mathrm{TiO}_{2}$, and the physical bacterial capture was the dominant disinfection mechanism. The authors found that high disinfection rate can be realized at an optimum MCNT: $\mathrm{TiO}_{2}$ ratio of 5:1, while the hydroxyl radical $\cdot \mathrm{OH}$ was reactive oxygen species on the photocatalytic disinfection using $\mathrm{MCNT}^{-\mathrm{TiO}_{2}}$. 
Additionally, Fu et al. developed onion like carbon (OLC) modified $\mathrm{TiO}_{2}$ composite coatings by suspension plasma spraying (SPS) using $\mathrm{TiO}_{2}$ and OLC nanoparticles as the starting nanomaterials (Ref 34). Nanostructured features of OLC and $\mathrm{TiO}_{2}$ particles were retained in the coatings and unique dispersion of the OLC particles in the coatings was achieved. The authors revealed that the addition of OLC nanoparticles enhanced the photocatalytic performances of the pure $\mathrm{TiO}_{2}$. The synergistic effect of OLC and $\mathrm{TiO}_{2}$ particles was further elaborated.

\section{Metal-Containing Photocatalysts Other than $\mathrm{TiO}_{2}$}

To achieve solar-driven disinfection of waterborne pathogens, a number of efficient, UV to visible-absorptive, metal-containing photocatalysts other than $\mathrm{TiO}_{2}$-based materials have been developed, including $\mathrm{ZnO}$ (Ref 35), $\mathrm{Bi}_{2} \mathrm{WO}_{6}$ (Ref 36), $\mathrm{WO}_{3}$ (Ref 37), $\mathrm{Ga}_{0.25} \mathrm{Zn}_{4.67} \mathrm{~S}_{5.08}$ (Ref 38), CuI (Ref 39), etc.

$\mathrm{ZnO}$ (which has a band gap of $3.37 \mathrm{eV}$ ) is abundant in nature, relatively inexpensive and strongly oxidative, which is similar with $\mathrm{TiO}_{2}$ when working as photocatalyst. $\mathrm{ZnO}$ nanoparticles are widely known for their enormous surface to volume ratio (Ref 40). However, the toxicity of the $\mathrm{ZnO}$ nanoparticles in water can pose threats to human health. In order to take advantage of the photocatalytic surface and the safe disposal of $\mathrm{ZnO}$, two ways of immobilization routes are developed. The first is to develop $\mathrm{ZnO}$ nanorods on flat substrates (e.g., glass) with seeded $\mathrm{ZnO}$, while the second route is to immobilize the $\mathrm{ZnO}$ nanomaterials onto membrane substrates.

As to the first case, Alarcon et al. prepared $\mathrm{ZnO}$ nanorods on a glass substrate, from seed layers fabricated from c-irradiated zinc acetate in a thermal bath of a basic zinc nitrate (Ref 41). Sanchez et al. reported immobilized $\mathrm{ZnO}$ nanorod films grown on $\mathrm{ZnO}$-seeded polyethylene terephthalate (PET) substrates in alkaline aqueous solution (Ref 42). Rodríguez et al. deposited $\mathrm{ZnO}$-seeded glass substrate by using a spray pyrolysis technique; then, they fabricated $\mathrm{ZnO}$ nanorod film from a mixed solution of $\mathrm{Zn}\left(\mathrm{NO}_{3}\right)_{2}$ and $\mathrm{NaOH}$. Benefited from larger surfaces of the nanorods, $\mathrm{ZnO}$ exhibited good efficiency in bacteria disinfection, and previous measurements showed that the efficiency of $\mathrm{ZnO}$ NRs samples correlates with the texture of the nanorod and the number of rods per area (Ref 43).

Ceramic membranes of nano porous anodic aluminum oxide (AAO) were employed to grow highly adherent $\mathrm{ZnO}$ nanostructured films (Ref 44). As shown in Fig. 2, Najma et al. developed highly porous networks of $\mathrm{ZnO}$ nanosheets on AAO substrate. The membranes were found highly reactive under UV irradiation and greatly deteriorated bacterial population in the nearby vicinity. Moreover, the membranes also showed an appreciable antibacterial activity in the dark experimental conditions. It was found that the bacterial degradation efficiency of the membranes reached $70 \%$ of their efficiency in UV light conditions after $16 \mathrm{~h}$ incubation in dark.

Ceramic substrate of clay minerals is another choice for the immobilization of $\mathrm{ZnO}$ photocatalyst particles, due to their abundance on earth surface, high porosity, thermal stability, and bio-compatibility. Among different clay materials, kaolinite has been widely used as a cosmetic and healing mineral and is expected to be safe for water treatment application. Ananyo et al. prepared immobilized $\mathrm{ZnO}$ nanoparticle photocatalyst on kaolinite substrate, which realized complete disinfection of multidrug resistant Enterobacter sp. within $120 \mathrm{~min}$ by visible-light-aided photocatalytic disinfection process, exhibiting bactericidal efficiency superior to conventional catalysts such as $\mathrm{TiO}_{2}$ and $\mathrm{ZnO}$ (Ref 45).

There are some other metal-containing photocatalysts developed in recent years, including $\mathrm{WO}_{3}$, Bi-based photocatalysts (such as $\mathrm{BiFeO}_{4}$ and $\mathrm{Bi}_{2} \mathrm{WO}_{6}$ ), several types of binary or ternary sulfides (such as $\mathrm{ZnS}, \mathrm{MoS}_{2}, \mathrm{CdS}$, and $\mathrm{Ga}-\mathrm{Zn}-\mathrm{S}$ ), iodide of precious metals (such as $\mathrm{CuI}$ ), all of which showed advantages in certain aspects (Ref 46-48).

Nanostructured $\mathrm{WO}_{3}$ is a visible-light responsive photocatalyst that absorbs light up to about $480 \mathrm{~nm}(2.58 \mathrm{eV})$. It has significant advantages of low cost, harmlessness, and stability in acidic and oxidative conditions. Various strategies, including noble metal deposition, surface hybridization with graphene oxide, were used to promote the photocatalytic activity of $\mathrm{WO}_{3} . \quad \mathrm{Pt}-\mathrm{WO}_{3}$ materials realized viral inactivation due to light-induced plasmon (Ref 49). Akhavan et al. incorporated graphene oxide (GO) sheets into $\mathrm{WO}_{3}$ films to form graphene- $\mathrm{WO}_{3}\left(\mathrm{G}-\mathrm{WO}_{3}\right)$ thin films, which was confirmed to be highly efficient in anti-virus use with long-term stability (Ref 50). In the future, it is yet necessary to develop immobilization routes to improve its photocatalytic activity toward practical applications.

Bi-based photocatalysts have been comprehensively investigated recently due to their excellent photocatalytic performance. For example, $\mathrm{Bi}_{2} \mathrm{WO}_{6}$ had a suitable band gap of around $2.8 \mathrm{eV}$, which was reported as an excellent visible-light-driven photocatalyst for $\mathrm{O}_{2}$ evolution or degradation of organic matters. By producing a heterojunction composite by coupling $\mathrm{Bi}_{2} \mathrm{WO}_{6}$ with $\mathrm{TiO}_{2}$, the photocatalytic activity can be greatly enhanced (Ref 51). According to $\mathrm{Xu}$ et al., $\mathrm{Bi}_{2} \mathrm{WO}_{6} / \mathrm{TiO}_{2}$ composite was successfully prepared by using a one-step hydrothermal method, and demonstrated better photocatalytic bactericidal effect for $E$. coli than single $\mathrm{Bi}_{2} \mathrm{WO}_{6}$ or $\mathrm{TiO}_{2}$. Additionally, Ji et al. synthesized a new ternary composite of $\mathrm{Bi}_{2} \mathrm{WO}_{6} / \mathrm{TiO}_{2} / \mathrm{rGO}$ by using a facile hydrothermal method for disinfection use (Fig. 3) (Ref 52). The reduced 
Fig. 2 Schematic illustration of photocatalytic degradation of E. coli by $\mathrm{ZnO} / \mathrm{AAO}$ composite membrane (Ref 44)

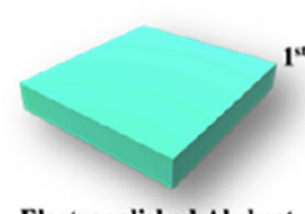

Electropolished Al sheet
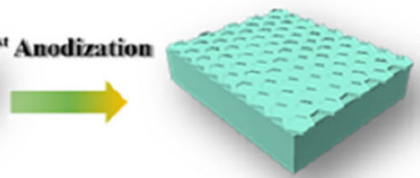

2"Anodization

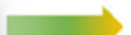

Al with periodic concaves after dissolution of oxide

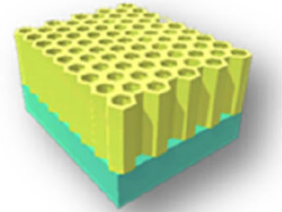

AAO/Al substrate

Solgel Treatment

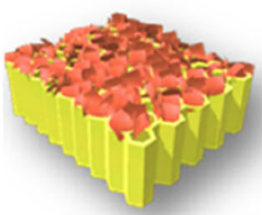

Free Standing

Membrane
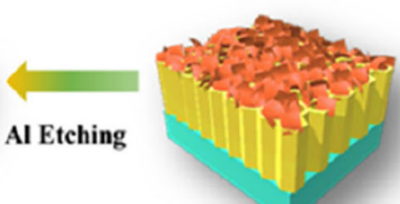

ZnO Nanosheet

Formation

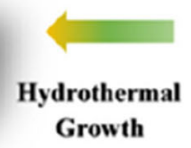

Growth

Seeded AAO substrate

\section{Potential (eV)}

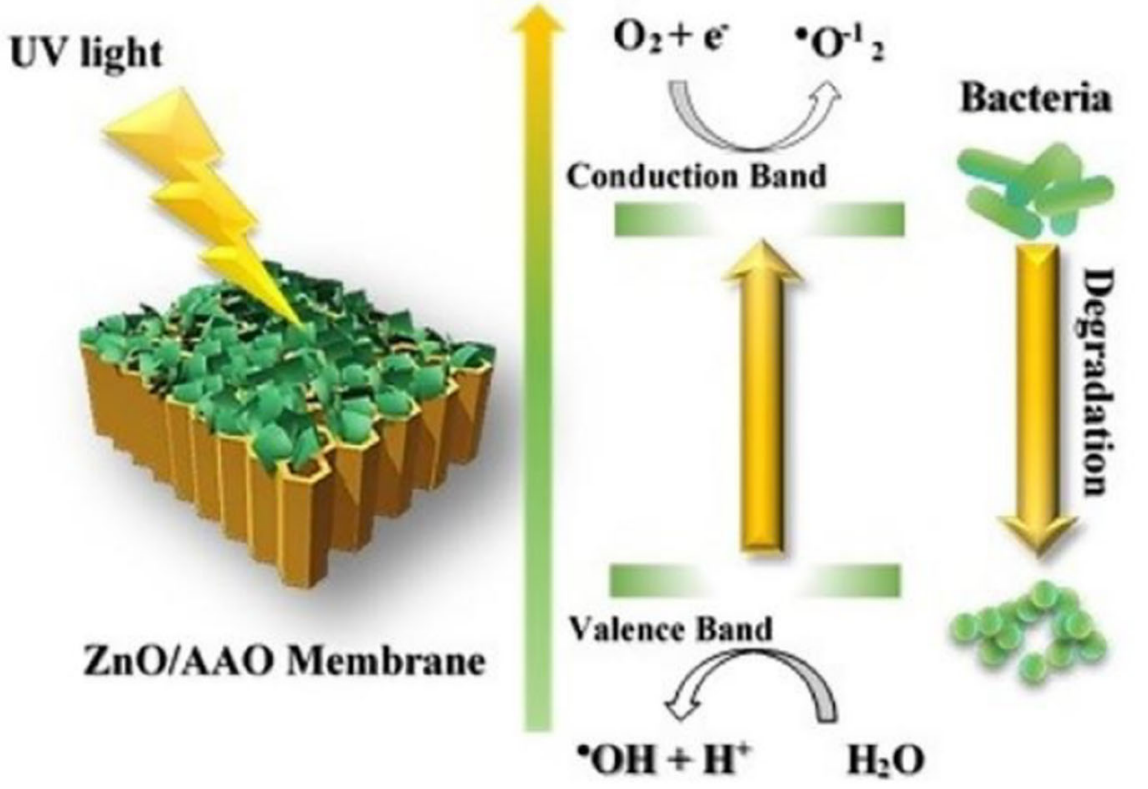

Fig. 3 Schematic illustration of the underlying photocatalytic mechanism for enhanced disinfection of $E$. coli by $\mathrm{Bi}_{2} \mathrm{WO}_{6} / \mathrm{TiO}_{2} / \mathrm{rGO}$ composites (Ref 52)

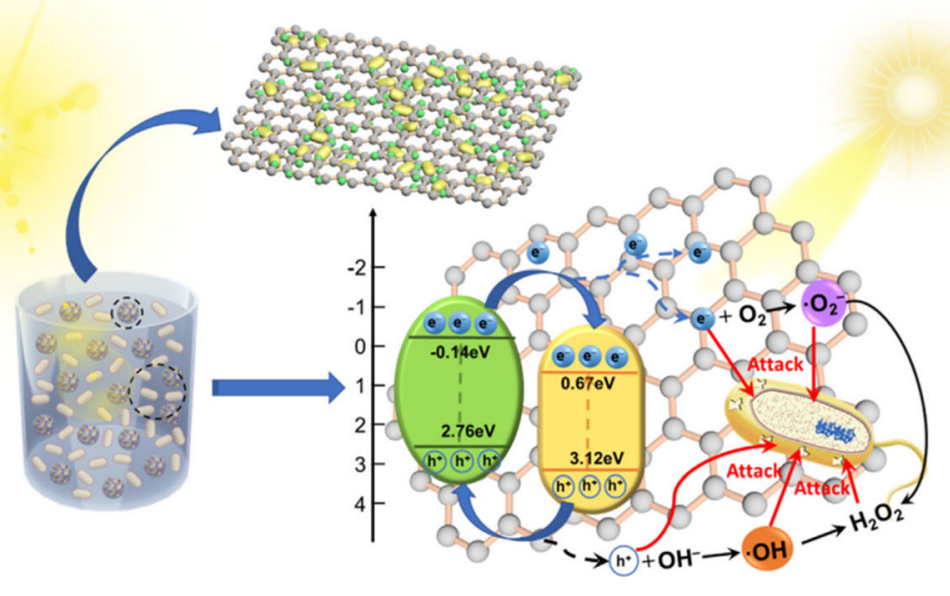


graphene materials promoted the separation of photocarriers and enhanced the visible absorption, and the $\mathrm{Bi}_{2} \mathrm{WO}_{6} /$ $\mathrm{TiO}_{2}$ heterojunction gave rise to photogenerated carriers for the disinfection process. The trapping experiments demonstrated that the photoinduced $\mathrm{h}^{+}$played a vital role in the disinfection of E. coli, while the derived $\cdot \mathrm{OH}, \mathrm{e}^{-}$, and $\mathrm{O}_{2}{ }^{-}$exhibited synergistic effects. Comparing to $\mathrm{Bi}_{2-}$ $\mathrm{WO}_{6}$ or $\mathrm{TiO}_{2}$, the ternary composite material exhibited enhanced visible-light-induced photocatalytic activity against E. coli. Moreover, $\mathrm{Li}$ et al. reported a $\mathrm{Pb}$-doped $\mathrm{BiFeO}_{3} / \mathrm{rGO}$ (reduced graphene oxide) photocatalytic disinfection material which was visible-light-driven and showed high chemical stability. The $\mathrm{Pb}-\mathrm{BiFeO}_{3} / \mathrm{rGO}$ photocatalyst exhibited the strongest bactericidal properties against E. coli $(100 \%)$ and S. aureus $(99.7 \%)$ after $1 \mathrm{~h}$ of visible-light irradiation for a $0.5 \%$ doping of rGO. High chemical stability was also found even after four reuse cycles (Ref 53).

Binary or Ternary sulfides, such as $\mathrm{ZnS}, \mathrm{CdS}, \mathrm{FeS}$, $\mathrm{Ga}_{2} \mathrm{~S}_{3}$, and $\mathrm{Ga}-\mathrm{Zn}-\mathrm{S}$ are chemically stable materials, which can be employed for photocatalytic disinfection purpose due to easy synthesis, low cost, high efficiency, and exceptional photoelectric properties. Zinc sulfide $(\mathrm{ZnS})$ has been a research focus recently due to its high negative reduction potentials electrons, exited by UV-visible light. Alafif et al. successfully fabricated zinc sulfide decorated sulfur-doped reduced graphene oxide (S-rGO/ZnS) nanocomposite by using a facile one-pot method (Ref 53). Their results showed that S-rGO/ZnS could effectively absorb visible light which may be ascribed to the heterojunction formation between $\mathrm{ZnS}$ and S-rGO, while the $\mathrm{S}$ doping in rGO was proven to enhance the electrical conductivity and electron trapping which suppresses the charge recombination. Taking into account the two benefits, S-rGO/ZnS nanocomposite can be utilized under solar light irradiation for the antibacterial process and purification of wastewater.

Cadmium sulfide (CdS) was extensively studied due to its band gap $(2.4 \mathrm{eV})$, corresponding well with the spectrum of sunlight, which makes it active under sunlight or visible light. Furthermore, it is inexpensive and can be easily synthesized through various reproducible methods. Gao et al. reported the fabrication and disinfection performance of graphene oxide (GO)-CdS composites, which were synthesized via a facile two-phase mixing method (Ref 54). The carbon network graphene oxide provides extraordinary conductivity and enlarged surface area, leading to improved photocatalytic disinfection efficiency. Photocatalytic antibacterial activity examination of the GO-CdS composites showed nearly $100 \%$ of both gramnegative E. coli and gram-positive Bacillus subtilis (B. subtilis) being killed within $25 \mathrm{~min}$ under visible-light irradiation.
The sulfide could also be used as an effective sensitizer for titania photocatalyst because of its high light harvesting efficiency. For instance, Song et al. fabricated titania nanotube arrays which were sensitized with pyrite $\mathrm{FeS}_{2}$ by using cathodic electrodeposition of $\mathrm{Fe} / \mathrm{Fe}_{2} \mathrm{O}_{3}$ followed by sulfurizing with evaporative sulfur (Ref 55). The much enhanced visible-light response and photocatalytic performance of the $\mathrm{FeS}_{2}$-sensitized film under the simulated solar light were revealed by the photo-electrical and photodegradation experiments.

Ternary sulfides were found to have narrower band gap and large absorption than $\mathrm{TiO}_{2}$ and $\mathrm{ZnO}$ catalysts. Among them, $\mathrm{Ga}_{2} \mathrm{~S}_{3}$ is an effective optoelectronic material which is stable and easy to adjust by introducing other metals. Yan et al. reported that $\mathrm{Ga}_{0.25} \mathrm{Zn}_{4.67} \mathrm{~S}_{5.08}$ microspheres prepared at $400{ }^{\circ} \mathrm{C}$ exhibited the best antibacterial performance, as evidenced by complete killing of E. coli K12 within $4 \mathrm{~h}$ (Ref 38).

Iodide of precious metals was studied for photocatalytic disinfection use. $\gamma$ phase $\mathrm{CuI}$ possesses smaller band gap $(3.1 \mathrm{eV})$ than $\mathrm{TiO}_{2}(3.2 \mathrm{eV})$. Furthermore, CuI adsorbs efficiently heavy metal ions; thus, it can be considered as a good candidate for water treatment. Wojtyla et al. investigated the role of visible-light-induced $\mathrm{Cu}^{+}$to $\mathrm{Cu}^{2+}$ transition in photocatalytic inactivation of microorganisms (Ref 39). It was found that the photosensitization mechanism encompasses a metal to metal charge transfer. The absorption edge of photosensitized $\mathrm{CuI}$ is red shifted toward a lower energy when compared with bare $\mathrm{CuI}$, resulting in enhanced visible-light-induced photocatalytic activity and photoactive in the degradation of organic compounds and inactivation of fungi (Saccharomyces cerevisiae).

\section{Metal-Free Photocatalysts}

Although most photocatalysts containing metals or heavy metals have been proven to be excelled in antiviral activity, the accidental leaching of toxic metals, such as $\mathrm{Cu}$ and $\mathrm{Ag}$, into treated water could cause serious health concerns. Therefore, there is an urgent need to develop metal-free "green" photocatalyst for inactivation of pathogenic microbes. In the following, we introduce three typical kinds of metal-free photocatalysts developed recently.

As a type of soccer ball-shaped-all-carbon molecule with excelled energy and electron transfer properties, $\mathrm{C}_{60}$ derivatives can be photoexcited under visible-light irradiation $(>2.3 \mathrm{eV})$; thus, the material holds promise for photo-reactive applications. When functionalized with hydrophilic moieties, water-soluble $\mathrm{C}_{60}$ derivatives can be dispersed uniformly in the solution, which can be used as antiviral photocatalysts (Ref 56). The cationic amino $\mathrm{C}_{60}$ exhibited exceptionally efficient viral inactivation even in 
comparison with commercial $\mathrm{P} 25$, which is probably due to the electrostatic attraction between positively charged $\mathrm{C}_{60}$ derivatives and negatively charged $\mathrm{MS}_{2}$ viruses. The design of $\mathrm{C}_{60}$-based photocatalysts for viral inactivation is illustrated in Fig. 4 (Ref 57-60).

Due to the large surface area and good absorptivity in visible band, metal-free GO (graphene oxide) has attracted considerable attention for photocatalysts. By immobilizing aptamers on the edge of GO, Hu et al. synthesized GOaptamer nanosheets that are highly efficient for anti-virus applications (Ref 61).

Other than photocatalysts based on $\mathrm{C}_{60}$ and GO, a newly developed graphitic carbon nitride $\left(\mathrm{g}-\mathrm{C}_{3} \mathrm{~N}_{4}\right)$ material has been found to be reactive under visible range, biocompatible, resistant to photo-corrosion or air oxidation, and chemically stable in solvents acids. A major shortcoming of implementing $\mathrm{g}-\mathrm{C}_{3} \mathrm{~N}_{4}$ for practical disinfection use are aggregation phenomena in water and difficulty in separation and recycle. Porous $\mathrm{g}_{-} \mathrm{C}_{3} \mathrm{~N}_{4}$ immobilized on the carrier of natural mineral of expanded perlite (EP) is a new route to tackle these challenges. As shown in Fig. 5, Zhang et al. developed a new composite photocatalyst from low-cost and earth-abundant materials, which possesses several advantages, including highly porous carrier with a large particle size of millimeters, promoting uniform dispersion of $\mathrm{g}_{-} \mathrm{C}_{3} \mathrm{~N}_{4}$ and good reusability, resistant to photo-corrosion, enhanced light utilization, ROS production, and thus antiviral performance. It was reported that the new photocatalyst inactivated all viruses under $240 \mathrm{~min}$ visible- (a)

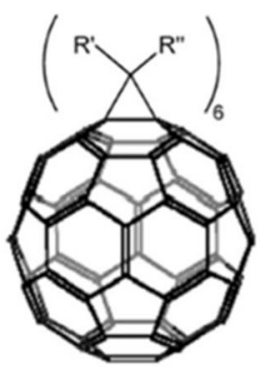

$\mathrm{HC} 1: \mathrm{R}^{\prime}=-\mathrm{CO}_{2} \mathrm{H} ; \mathrm{R}^{\prime \prime}=-\mathrm{CO}_{2} \mathrm{H}$

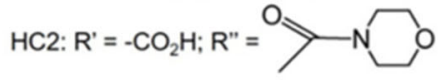

(b)
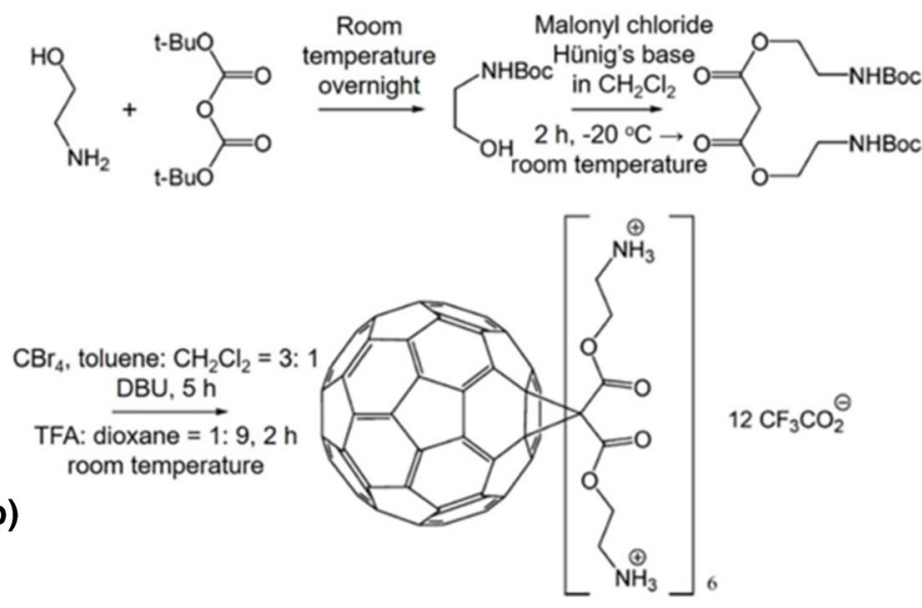

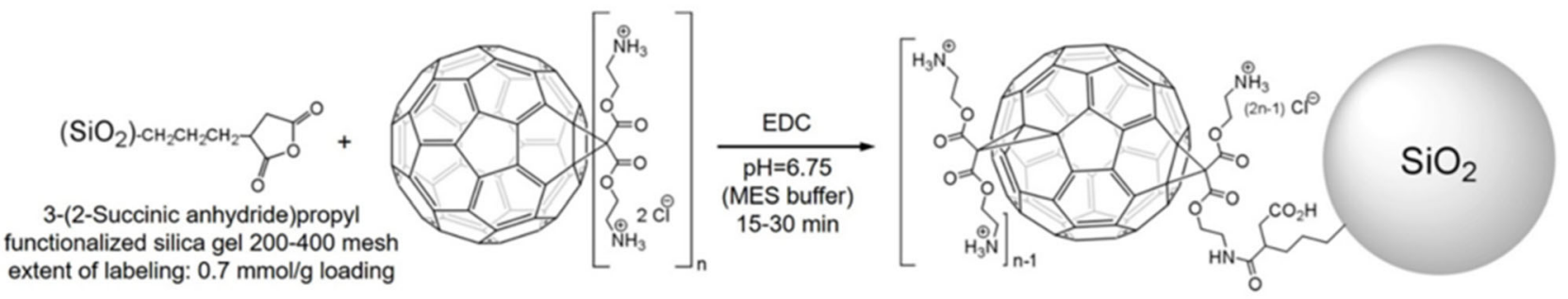

(c)

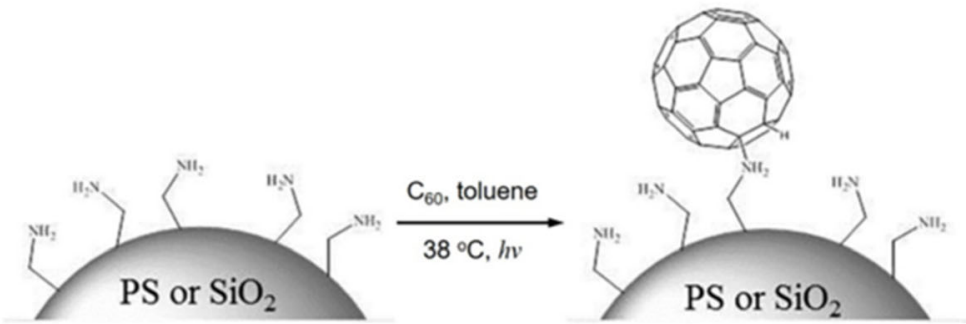

(d)

Fig. 4 Design developments of $\mathrm{C}_{60}$-based photocatalysts for viral inactivation: (a) chemical structures of $\mathrm{C}_{60}$ derivatives (Ref 57), (b) synthesis of cationic amino $\mathrm{C}_{60}$ (Ref 58), (c) strategy for immobilization of amino $\mathrm{C}_{60}$ on functionalized $\mathrm{SiO}_{2}$ (Ref 59), (d) direct amine addition strategy for immobilization of pristine $\mathrm{C}_{60}$ on $\mathrm{SiO}_{2}$ (Ref 56), and (e) UV/Vis spectra of $\mathrm{C}_{60}$ and $\mathrm{C}_{70}$ and schematic diagram of viral inactivation induced by $\mathrm{C}_{70} / \mathrm{SiO}_{2}$ (Ref 60) 
Fig. 5 Photocatalytic antiviral and antibacterial mechanisms of porous $\mathrm{EP} / \mathrm{g}-\mathrm{C}_{3} \mathrm{~N}_{4}$ (Ref 62)

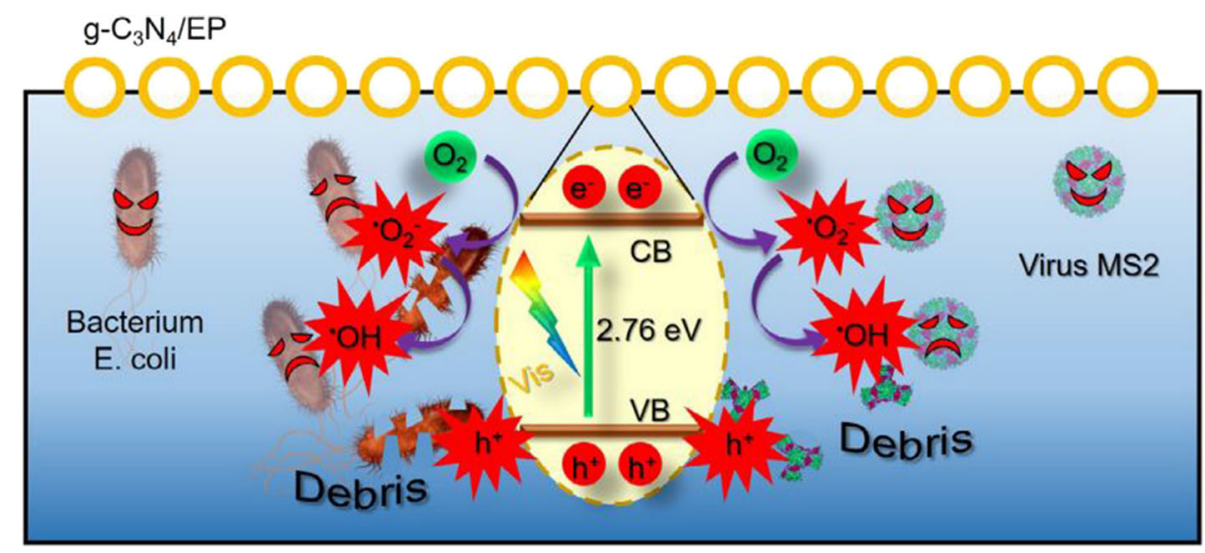

light irradiation (Ref 62), as a comparison, only $77.1 \%$ of E. coli bacteria can be killed by bulk $\mathrm{g}-\mathrm{C}_{3} \mathrm{~N}_{4}$.

\section{Two-Dimensional Photocatalysts}

Two-dimensional (2D) nanomaterials have become a rising star in developing photocatalysts for their confined thickness and specific surface area, exhibiting unique structural, physical and chemical properties. Compared to OD and 1D nanomaterials, 2D nanostructures show obvious superiorities in architecture modulation, charge separation, light harvesting and tunability. There are several merits of $2 \mathrm{D}$ photocatalysts. Large lateral size of 2D nanosheets offers plenty of active sites for surface reaction. The plane surface is beneficial for accommodating guest components for the formation of a heterojunction. In addition, the ultrathin thickness promotes the charge diffusion to the surface by shortening the transportation. Moreover, the flexibility of 2D layers enlarges the exposed area for light harvesting. Furthermore, the band gap and absorption of 2D semiconductors are adjustable by simply tuning the thickness of the nanolayers.

Inspired by the unique properties of $2 \mathrm{D}$ structured materials, numerous efforts have been devoted to developing highly efficient 2D photocatalysts, as well as exploring their potential in disinfection applications. Many kinds of 2D photocatalysts are being developed recently, including 2D metal oxides, graphene, graphitic carbon nitride, metal oxyhalides, and transition metal dichalcogenides (Ref 63). As typical representatives, the photo-

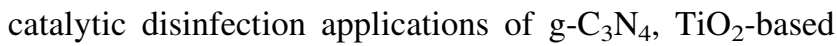
photocatalysts and $\mathrm{MoS}_{2}$ are presented in the following sections.

The photocatalytic efficiency of bulk $\mathrm{g}-\mathrm{C}_{3} \mathrm{~N}_{4}$ is limited by high carrier recombination rate and low surface area. According to Ong, laminar structured g-C3N4 showed several advantages as compared to bulk samples. Further work was carried out by $\mathrm{Xu}$ et al., who fabricated porous g- $\mathrm{C}_{3} \mathrm{~N}_{4}$ nanosheets (PCNS) via a two-step process, i.e., hydrothermal treatment and thermal etching (Ref 64). E. coli bacteria were completely killed within $4 \mathrm{~h}$ by PCNS. In comparison, there are 77.1 and $89.6 \%$ of the bacteria still remained during the tests for bulk $\mathrm{g}-\mathrm{C}_{3} \mathrm{~N}_{4}$ and porous $\mathrm{g}-\mathrm{C}_{3} \mathrm{~N}_{4}$ under the same testing conditions. The improved photocatalytic ability was attributed to the improved porosity and enlarged surface area, which facilitate efficient charge carrier separation. Furthermore, the band gap was expanded due to the limited thickness, causing a strengthened photo-redox performance.

Most of the $\mathrm{TiO}_{2}$-based photocatalyst for disinfection pertained to the use of nanoparticles, nanotubes or so on. A few studies have been carried out on applying $2 \mathrm{D} \mathrm{TiO}_{2}$. According to $\mathrm{Ma}$ et al., $\mathrm{Fe}_{3} \mathrm{O}_{4}$ nanoparticles were deposited on $\mathrm{TiO}_{2}$ nanosheets (TNS) to serve as an electron acceptor and enable magnetic separation (Ref 65). Bactericidal testing showed a higher microbe removal percentage $\left(92.7 \%\right.$ in $2 \mathrm{~h}$ ) for the hybrid than the pure TNS or $\mathrm{Fe}_{3} \mathrm{O}_{4}$. Increasing the immobility of antibacterial nanomaterials is an important strategy for their reusability. In this regard, Wang et al. coated the TNS onto glass films layer by layer after exfoliating titanium oxide into ultrathin nanosheets, and then, the device was used for photocatalytic microbe inactivation (Ref 66). The extraordinary thin coating layer was nearly transparent in UV-Vis spectrum. However, the functional photocatalytic layer could still perform disinfection effect when illuminated, which was attributed to the electron storage ability of the multi state Ti. The photocatalytic film was effective after 5 cycles of operation, indicating its good potential for water purification. Moreover, Zhang et al. reported a $\mathrm{TiO}_{2}$-based catalytic film with dark inactivation ability. A layer of $\mathrm{TiO}_{2}$ seeds was firstly deposited on glass using sol-gel method. Then, the $\mathrm{TiO}_{2}$ seeds grew onto Ag-embedded parallel nanosheets after solvothermal treatment in $\mathrm{TiO}_{2}$ and $\mathrm{AgNO}_{3}$ sol, forming a catalytic coating on the glass surface (Ref 67 ). The photocatalytic film exhibited bactericidal performance of almost $100 \%(365 \mathrm{~nm}, 24 \mathrm{~h})$, and it also achieved a sterilizing rate of above $99 \%$ to both gram-negative and gram- 
positive bacteria in dark. The Ag particles played a dual role in the antibacterial process: electron acceptor and cytotoxicity.

Few-layered $\mathrm{MoS}_{2}$ nanosheets (NSs) have the advantages of being able to harvest the whole spectrum of visible light (approximately $50 \%$ of solar energy) and have been reported to effectively generate photocatalytic reactions, which presented superior catalytic activity and disinfection performance owing mainly to prolonged electron-hole pair (EHP) lifetime. Chou et al. (Ref 68) reported a single- and few-layered $\mathrm{MoS}_{2}$ decorated with Au nanoparticles (NPS) as a new efficient nanocatalyst that can be simply activated by ambient mechanical force and light excited electronhole pairs, as shown in Fig. 6(a). After deposition of Au NPs, 99.999\% reduction in bacteria can be achieved by visible-light irradiation for $60 \mathrm{~min}$, while the required treatment time can be reduced to 15 min under a combination of mechanical vibration and IR light irradiation (Fig. 6b, c, and d).

\section{Thermal-Sprayed Photocatalytic Coatings}

The photocatalytic particles can be used for disinfection of a wide range of microbes (e.g., pathogenic bacteria, viruses, and fungi) with the advantages of ease in use and high efficiency. However, the suspended photocatalytic powers have the shortcomings including difficulty in separation and recycling. Moreover, leakage of the photocatalytic nanomaterials in most cases may cause secondary pollution. Therefore, practically, the photocatalytic nanoparticles should be immobilized onto the surface of a certain substrate (e.g., quartz, steel, polymer, etc.) in a large scale so as to produce mechanically stable coatings. Thermal spray photocatalytic techniques offer the advantages of low

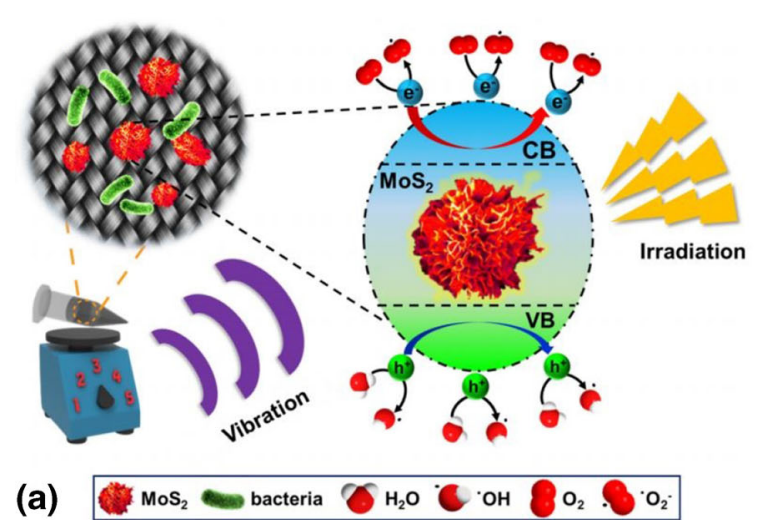

Fig. 6 (a) Schematic diagram of the Au-MoS 2 nanocatalyst for water disinfection application. (b) Illustration of $\mathrm{Au}-\mathrm{MoS}_{2} @ \mathrm{CFs}$ achieving bacterial disinfection under light irradiation. (c) Disinfection performance of the control (pure bacteria), $\mathrm{MoS}_{2} @ \mathrm{CFs}$ and Au-MoS $\mathrm{M}_{2} @ \mathrm{CFs}$

cost, wide selection of coating materials, and easy on-site operation, making it promising for the fabrication of largescale photocatalytic coatings. Divided by different working modes, the thermal spray techniques include but are not limited to atmosphere plasma spray (APS), suspension plasma spray (SPS), flame spray, high-velocity oxy-fuel (HVOF) spray and cold spray, which are important in photocatalytic disinfection applications (Ref 69-71). A novel low pressure cold gas spraying technique was used to large-scaled fabrication of carbon-modified $\mathrm{TiO}_{2}$ photocatalytic coatings as shown in Fig. 7. In this section, the fabrication methods, coating microstructures, as well as the photocatalytic disinfection mechanisms, performances and applications of thermal-sprayed coatings in eight different emerging trends are reviewed.

\section{Visible-Light-Induced Photocatalytic Coatings}

There is only $\sim 4-5 \%$ of solar light being within the UV range, while the visible light contributes about $50 \%$ of the total power. Therefore, many attempts were made to attain visible-light-induced photocatalytic activities, for instance, structure modification, metal and nonmetal doping, co-deposition of metals, and mixing of two semiconductors (Ref 72-75).

The visible absorptance of the photocatalysts can be greatly improved by using modified $\mathrm{TiO}_{2}$ powders or nanotubes via different synthesis routes, leading to improvement in disinfection efficiency. According to Birben et al., N-doped, Se-doped, and Se-N co-doped $\mathrm{TiO}_{2}$ showed visible light activated photocatalytic disinfection efficiency (Ref 76), whereas undoped $\mathrm{TiO}_{2}$ displayed comparatively slower removal rates of $E$. coli than the doped and co-doped $\mathrm{TiO}_{2}$ specimens. Additionally, Koklic et al. investigated the visible driven photocatalytic

(b)

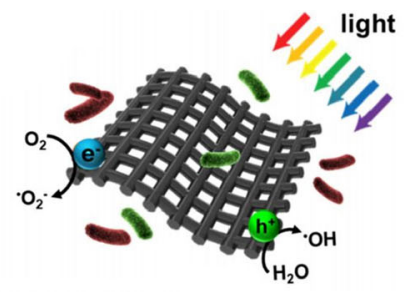

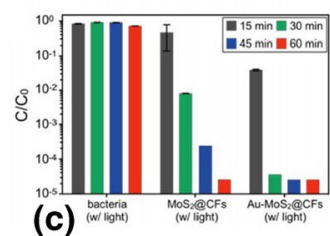

under visible-light irradiation. (d) Disinfection performance of Au$\mathrm{MoS}_{2} @ \mathrm{CFs}$ under a combination of mechanical vibration and IR light irradiation (Ref 68) 


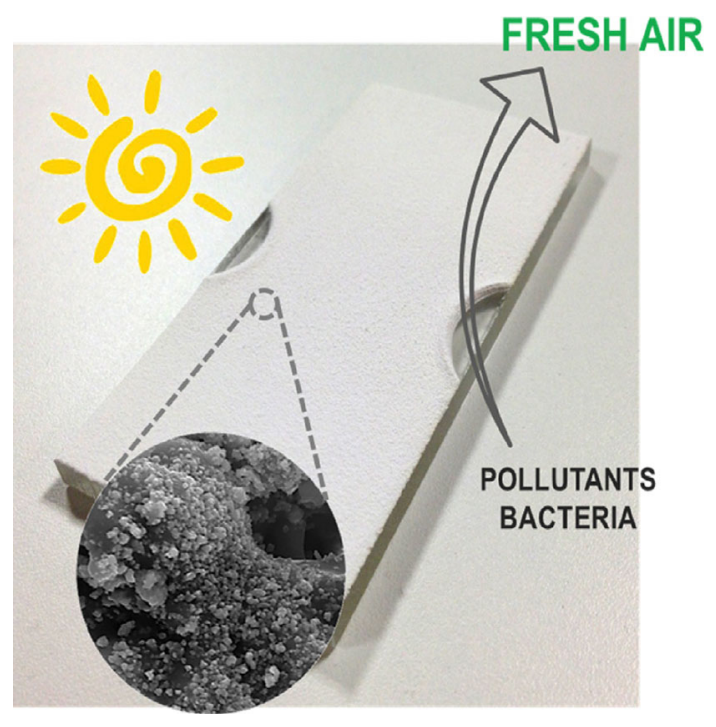

Fig. 7 Top surface of the cold-sprayed carbon-modified $\mathrm{TiO}_{2}$ photocatalytic coating (Ref 71)

disinfection properties of copper-doped $\mathrm{TiO}_{2}$ nanotubes deposited on existing surfaces. It was found that the ceiling mounted fluorescent light can retard the growth of Listeria innocua by $80 \%$ in $7 \mathrm{~h}$ of exposure to fluorescent light (Ref 77). Furthermore, Feilizadeh et al. prepared Fe-Cd codoped photocatalytic powders to realize the inactivation process by visible light. Based on the experimental data and a semi-empirical model, the authors predicted that the $\mathrm{Fe}-\mathrm{Cd} / \mathrm{TiO}_{2}$ catalyst was able to achieve a bacterial inactivation efficiency of $99.9 \%$ after 45 min of visible-light illumination (Ref 78).

For practical disinfection application, researchers have used thermal-sprayed $\mathrm{TiO}_{2}$ coatings. According to Bettini, an anatase/rutile mixed-phase photocatalyst was reported in the form of nanostructured powders by flame spray pyrolysis (FSP) method (Ref 79), which showed photocatalytic activity under sole visible light, indicating the potential of the FSP-made powders as indoor photocatalysts for disinfection purposes. A more practical study by $\mathrm{M}$. Nararom et al. was conducted using a thermal-sprayed $\mathrm{TiO}_{2}$ coating on plates (Ref 80). A parabolic concentrator to enhance the power density of the solar radiation for the disinfection of water containing E. coli. Acrylic matt black spray was used to prepare black reactor, which was proved to be more efficient for the inactivation of bacteria due to higher efficiency in absorbing photons to damage the bacteria. By using an optimized setup, effective inactivation of bacteria by approximately $4 \operatorname{logs}$ were achieved within $90 \mathrm{~min}$.

Doping with metals or constructing heterostructures were considered to be beneficial to the visible-light-induced photocatalytic activity or disinfection efficiencies. According to $\mathrm{P}$. Ctibor et al., iron-doped $\mathrm{TiO}_{2}$ coatings were prepared using atmospheric plasma spraying method with water- and gas-stabilized guns (Ref 81). Presence of $\mathrm{FeTiO}_{3}$ was detected in water-stabilized plasma sprayed coatings, which were more photocatalytically active than undoped coatings. In comparison, hydrogen-rich atmosphere in the gas stabilized plasma spray led to the reduction of certain amount of iron oxides to metallic iron. Consequently, the charge-transfer transition by UV or visible excitation between dopant ions via the conduction band took place in the coating, leading to improvement in butane conversion. However, the disinfection performance of the coatings was still unreported. George et al. reported that flame sprayed $\mathrm{Cu}$-doped $\mathrm{TiO}_{2}$ coating contained limited anatase phase due to the high growth temperature, while it still killed approximately $75 \%$ of $P A K$ bacterial cells after $3 \mathrm{~h}$ under white light illumination $(400-700 \mathrm{~nm})$, showing the same bactericidal capabilities as pure copper surfaces. Hence, the toxicity of $\mathrm{Cu}$ could exhibit synergistic effect with photocatalysis in disinfection applications (Ref 82). Moreover, Zhai et al. reported suspension plasma sprayed $\mathrm{TiO}_{2}-\mathrm{SrCO}_{3}$ heterostructure nanomaterial coatings for visible-light-induced disinfection, which exhibited superior bactericidal activities against $E$. coli to that of the pure $\mathrm{TiO}_{2}$ coatings, achieving a killing rate of over $99.7 \%$ within about $4 \mathrm{~h}(\operatorname{Ref} 83)$.

\section{Black $\mathrm{TiO}_{2}$ Photocatalytic Coatings}

$\mathrm{TiO}_{2}$ is one of the most widely used photocatalysts; however, the wide band gap of $\mathrm{TiO}_{2}(3.2$ and $3 \mathrm{eV}$ for anatase and rutile $\mathrm{TiO}_{2}$, respectively) and rapid charge recombination are the main shortcomings toward its practical applications. Extensive efforts were made to achieve visible-light photocatalytic activity through constructing intrinsic defects or making doping. Among the modified $\mathrm{TiO}_{2}$, black $\mathrm{TiO}_{2}$ showed excelled absorptivity in ultra violet to infrared range and were widely used for solar energy utilization (Ref 84), photodegradation (Ref 85), electrocatalysis (Ref 86, 87), among others.

It was recently realized that black $\mathrm{TiO}_{2}$ has much better photocatalytic activities than other structured $\mathrm{TiO}_{2}$. Zhou et al. synthesized a series of nitrogen-doped black $\mathrm{TiO}_{2}$ nanocatalysts via a one-step method. It was found that the urea addition inhibits the anatase to rutile phase transformation and also the formation of black $\mathrm{TiO}_{2}$ by $\mathrm{N}$ doping. The black $\mathrm{TiO}_{2}$ had more efficient excited charge separation and higher photocatalytic efficiency for algae inactivation (Ref 88). Furthermore, to facilitate the application of black $\mathrm{TiO}_{2}$, Zhai et al. fabricated black $\mathrm{TiO}_{2}$ coatings by using a suspension plasma spray (SPS) method. Black $\mathrm{TiO}_{2}$ coatings with porous microstructures and high photocatalytic activity were realized (Ref 21), as shown in Fig. 8 . The high temperature during the spray processing triggered 
Fig. 8 Digital photographs and topographical morphology of the white $\mathrm{TiO}_{2}$ coating (A) and the black $\mathrm{TiO}_{2}$ coating (B) fabricated by suspension plasma spraying. (-3 is enlarged view of selected area in -2) (Ref 21)
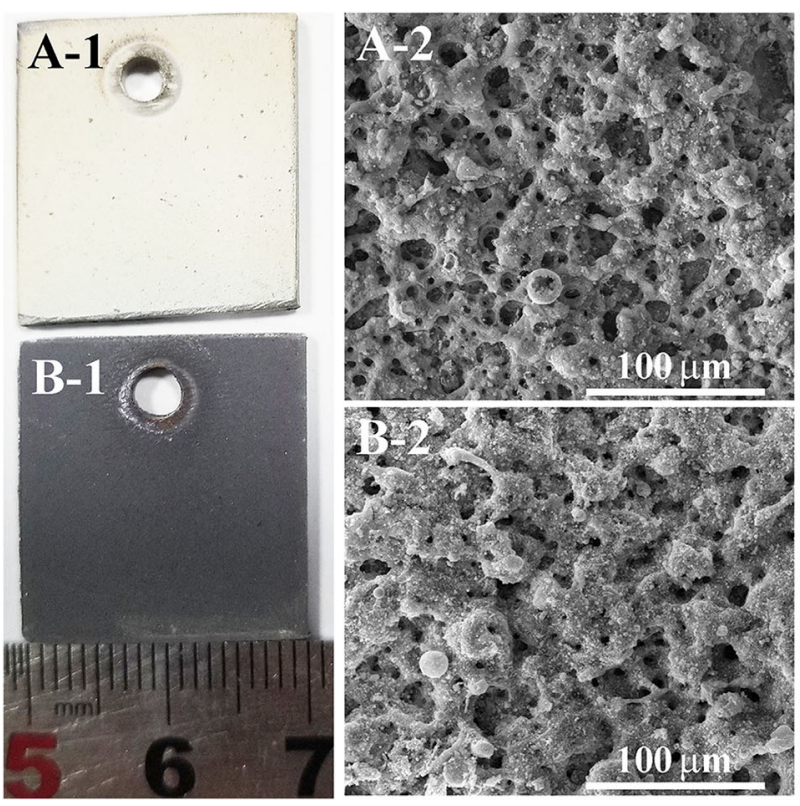

partial structure transformations of anatase to rutile, brookite, and remarkable lattice disorders of anatase, which significantly narrowed the band gap to $2.71 \mathrm{eV}$. The enhancement in solar absorption therefore increases its photocatalytic efficiency.

\section{Porous Heterostructured Photocatalytic Coatings}

Porosity is a vital factor that influences photocatalytic performances of photocatalytic coatings. Photocatalytic disinfection efficiency of porous photocatalyst is usually desired, for large surface area usually facilitates multiple light scattering effect and accelerated diffusion of ion species. Porous structures also lead to improved efficiency in generating ROSs products (e.g., $\mathrm{O}^{2-}, \mathrm{H}_{2} \mathrm{O}_{2}$, holes) that are crucial for bacteria inactivation. For viral and fungal inactivation, porous surface can shorten the diffusion pathway of the short-lived radicals (e.g., $\cdot \mathrm{OH})$ with high oxidizing power and promote their concentration, which are vital for the denaturing process of the rigid protein shells of virus, or the cell wall of fungi. Moreover, porous photocatalyst offers plenty of sites for anchoring active nanoparticles (NPs). Formation of the photocatalyst-NPs heterostructures will improve the separation efficiency of charge carriers and production of ROSs, which largely enhances the photocatalytic disinfection efficiency.

There is a number of routes to increase the porosity of the photocatalysts, including choosing organic fibers or mesoporous substrates, or synthesize microsphere shaped particles. According to $\mathrm{Xu}$ et al., $\mathrm{TiO}_{2}$ nanowires were precipitated on polyester fabrics through multi-steps of surface roughening, sol-gel $\mathrm{TiO}_{2}$ seeding, hydrogen titanate nanobelts precipitation, and sulfuric acid treatment
(Ref 89). Both mesoporous anatase $\mathrm{TiO}_{2}$ nanowires and single-crystalline rutile $\mathrm{TiO}_{2}$ nanorods have been achieved, which exhibited remarkable sterilization of E. coli and $S$. epidermidis. Additionally, Purbia et al. synthesized C-doped anatase $\mathrm{TiO}_{2}$ multi-tubes by using banana stem fiber as sacrificial template. High surface area $\left(\sim 99 \mathrm{~m}^{2} / \mathrm{g}\right)$ with a mesoporous structure made of $\sim 15 \pm 3 \mathrm{~nm}$ nanoparticles were reported, which exhibited enhanced light absorption property in visible region and excellent photocatalytic activity (Ref 90). Furthermore, Zhang et al. prepared porous $\mathrm{g}-\mathrm{C}_{3} \mathrm{~N}_{4}$ by loading graphitic $\mathrm{g}-\mathrm{C}_{3} \mathrm{~N}_{4}$ onto expanded perlite (EP) support through a facile hydrothermal process. $\mathrm{EP} / \mathrm{g}-\mathrm{C}_{3} \mathrm{~N}_{4}$ exhibited excellent antibacterial activity against E. coli (8-log reduction) and antiviral activity $\left(M S_{2}\right.$ phage $)$ under visible-light exposure of 180 and $240 \mathrm{~min}$, respectively (Ref 62). Yan et al. reported that $\mathrm{Ga}_{0.25} \mathrm{Zn}_{4.67} \mathrm{~S}_{5.08}$ microspheres prepared at $400{ }^{\circ} \mathrm{C}$ exhibited the best antibacterial performance, which attained complete killing of E. coli K12 within $4 \mathrm{~h}$. The authors attributed the superior photocatalytic activity to high specific surface areas and narrowed band gap (Ref 38). All these studies improved the disinfection performance of the photocatalyst by taking advantage of the high porosity.

Developing micro/mesoporous surface and visible active photocatalysts on a large scale is a promising task from the practical perspective. Thermal spray is an important fabrication route to realize porous photocatalytic structures. Recently, some researchers focused on the doping/processing-porosity-property correlation of thermal-sprayed $\mathrm{TiO}_{2}$ coatings. It was found that their photoactivity was comparable favorably to that of chemical vapor deposition (CVD) coatings and compressed P25 disks, where the bimodal-sized porosity was believed to be 

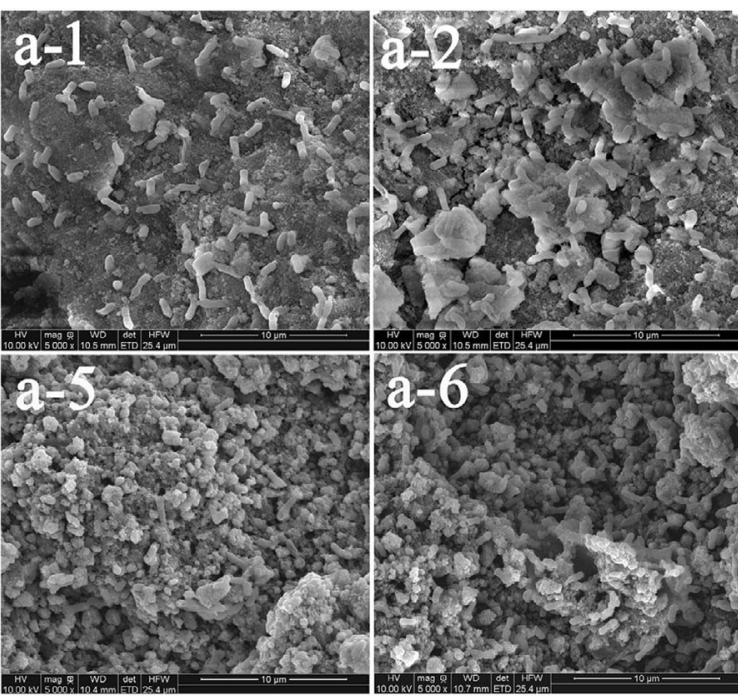

Fig. 9 Addition of HA-rGO in $\mathrm{TiO}_{2}$ coatings effectively increases the specific surface area of the coatings and markedly enhances recruitment of $E$. coli for subsequent photocatalytic elimination. (a) SEM images of $E$. coli adhered on the coatings after incubation for $6 \mathrm{~h}$; -1: the pure HA coating, -2: the HA-rGO coating, -3: the pure

optimal for desired photocatalytic performances (Ref 91, 92). Sugiyama et al. fabricated porous $\mathrm{TiO}_{2}$ coatings with uniform porosity along depth direction by a modified spray pyrolysis deposition (SPD) technique, where the porous surface with an effective area eight times higher than that of the non-porous sample was achieved. Consequently, the photocatalytic ability was enhanced by $2.5-2.8$ times (Ref 93). Additionally, Jbeli et al. investigated the synthesis and physical properties of $\mathrm{Fe}$-doped $\mathrm{La}_{2} \mathrm{O}_{3}$ coatings grown by spray pyrolysis with a doping rate of $0-5 \%$. The optimal photocatalytic activity was reached at the doping rate of $4 \%$, due to its dispersed and distorted porous structure constituted by small nanoparticles (Ref 94). Moreover, Zhang et al. found that the lower plasma power and higher powder feeding rate resulted in formation of higher porosity content in the plasma sprayed $\mathrm{TiO}_{2}$ coating, where the porosity has a dominating effect deciding the photocatalytic performance (Ref 95). The improvement in the photocatalytic performance of these porous coatings were proved via photodegradation of the subject matters, where the photocatalytic disinfection ability of the coatings is yet to be reported.

Therefore, for versatile environmental applications, extensive research efforts have been devoted to achieving large-scale photocatalytic coatings. According to Lin et al., mesoporous $\mathrm{TiO}_{2}$ nanocrystalline (NC) membranes with average pore size of $0.35 \mu \mathrm{m}$ were successfully fabricated by coating on an alumina support via a rapid atmospheric plasma spray (APS) approach (Ref 96). The photodegradation experiments of dextran and humic acid prove its potential in photodegradation of bio-organisms and protein

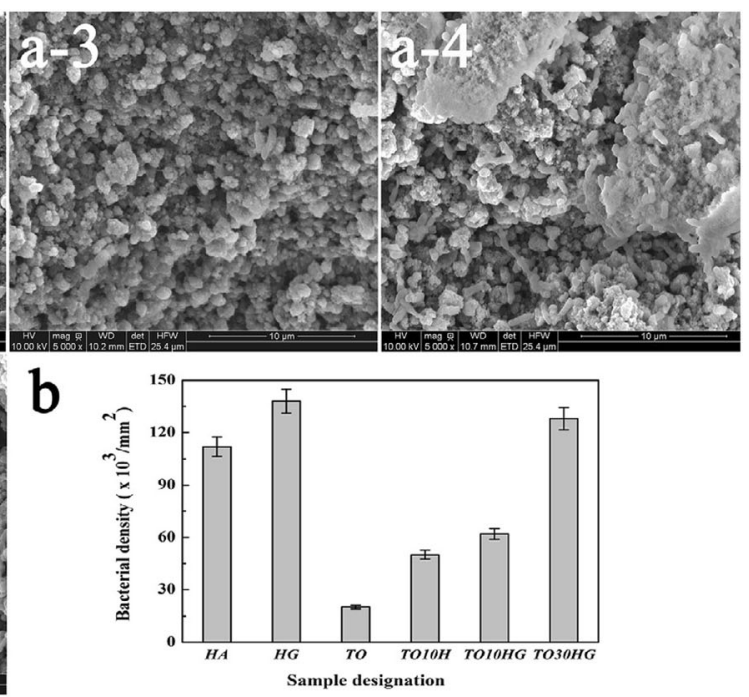

titania coating, -4 : the $\mathrm{TiO}_{2}-10 \mathrm{wt} \% \mathrm{HA}$ coating, -5 : the $\mathrm{TiO}_{2-}$ 10 wt. $\%$ (HA-rGO) coating, -6 : the $\mathrm{TiO}_{2}-30$ wt. $\%$ (HA-rGO) coating, and (b) bacterial density as determined by statistical counting of the E. coli adhered on the surfaces of the coatings (Ref 100)

under UV light irradiation, which is essential in photocatalytic disinfection. Additionally, M. C. Bordes prepared $\mathrm{TiO}_{2}$ photocatalytic coatings by APS from different feedstocks (Ref 97). The feedstocks were obtained by spray drying suspensions of a nano- and a submicron-sized $\mathrm{TiO}_{2}$ powder, with different solids contents and/or ratios of the nano- to submicron-sized particles. It was revealed that the coating porosity as well as the amount of partially melted areas depended strongly on plasma spray conditions and on feedstock characteristics. In another work, Kim et al. investigated the photocatalytic property of plasma sprayed $\mathrm{TiO}_{2}$ coating on foamed waste-glass substrates (Ref 98). The porous coating sample was found to be efficient in purify the green tide and the red tide when illuminated by UV light, where the nano-sized commercial $\mathrm{TiO}_{2}$ particle and mesoporous structure of the foamed glass improve the photocatalytic efficiency. Moreover, Mcfarlane et al. studied the sterilization mechanism of three different microbes (P. aeruginosa, $S$. aureus, $C$. albicans) by using jet spray formed titanium dioxide surfaces (Ref 99). The authors point out two important factors that are responsible for the high efficiency of inactivation: the high surface area of the porous nanomaterial and the direct contact between the microorganisms and the UV-activated surface. Furthermore, Zhai et al. reported suspension plasma sprayed $\mathrm{TiO}_{2}-\mathrm{SrCO}_{3}$ heterostructure nanomaterial coatings for the first time (Ref 83). The $\mathrm{TiO}_{2}-\mathrm{SrCO}_{3}$ co-catalyst with semiconductor heterostructures show significantly superior bactericidal activities against $E$. coli, which is partly attributed to the novel porous structure of the coating. 


\section{Bacteria Recruitment and Killing Strategies}

To achieve effective sterilization, the photocatalytic material must essentially favor the attachment of bacteria because of the short lifetime and diffusion length of the released ROSs. Support for the photocatalytic nanoparticles is able to limit the aggregation phenomena of the particles and contribute to the efficient spatial separation between the photogenerated electrons and holes. Therefore, by using the biocompatible supporting materials (e.g., zeolite, perlite, hydroxyapatite (HA), reduced graphene oxide (rGO), etc.) as baits, the recruitment and killing strategies have been a research focus. The bactericidal effect can be improved by enhancing the adsorption of bacteria and optimizing the ROSs radical generation on the supports by using these strategies (Ref 100-105).

Zeolites are crystalline aluminosilicates with regular dimension structure, channels and cavities called micropores, which can be used as the bait of the recruitment. Reddy et al. investigated the photocatalytic bactericidal activity of $\mathrm{TiO}_{2}$ supported over different support systems of $\mathrm{HY}, \mathrm{H} \beta, \mathrm{HZSM}-5$ and $\mathrm{SiO}_{2}-\mathrm{Al}_{2} \mathrm{O}_{3}$ systems (Ref 101). It was observed that $\mathrm{H} \beta$ zeolite exhibited the most mechanical adsorption of negative surface charged bacterial cells among the selected supports, which in turn enhanced the bactericidal activity given by $\mathrm{OH}$ radicals generated by photocatalytic $\mathrm{TiO}_{2}$ under light irradiation. Based on the experimental results, $5 \mathrm{wt} . \% \mathrm{TiO}_{2}$ loading over $\mathrm{H} \beta$ is sufficient to get higher bactericidal activity in comparison with $\mathrm{TiO}_{2}$ solely. The shortcoming is that the samples were prepared by mixing the supports with $\mathrm{TiO}_{2}$ in an agate mortar using dry ethanol, which limits its yields for practical application.

Thermal spray method has been used to prepare composite materials of support and photocatalysts in a large scale. As a highly porous and chemically inert media, perlite granules can act as a good adsorbent and support for $\mathrm{TiO}_{2}$ photocatalysts. M. Giannouri et al. presents the onestep synthesis of the $\mathrm{TiO}_{2}$ /perlite composites by flame spray pyrolysis (FSP) processing. The composite samples exhibited improved photocatalytic activity in comparison with commercial $\mathrm{TiO}_{2} \mathrm{P} 25$. However, the disinfection performance of $\mathrm{TiO}_{2}$ /perlite composites is yet to be reported (Ref 102) $\mathrm{TiO}_{2}$-hydroxyapatite (HAp) hybrid films were proved to be candidates for photocatalytic decomposition of germs, viruses by Nakajima et al. through spray pyrolysis deposition (SPD) method (Ref 103). Liu et al. prepared photocatalytic $\mathrm{TiO}_{2}$-HA coatings with significantly promoted adherence of $E$. coli bacteria (Ref 104), since HA is essentially biomedical material that bacteria like to stay on. It was also revealed that the coatings consisting of $10 \mathrm{wt} . \%$ HA showed the best photocatalytic activity, which is comparable to that exhibited by immobilized Degussa P25 coating. However, the photocatalytic disinfection mechanisms of $E$. coli were not discussed in the study. To further investigate the antibacterial mechanism, Huang et al. fabricated two types of $\mathrm{TiO}_{2}$-HA nanocomposites $\left(\mathrm{TiO}_{2}-\mathrm{HA}, \mathrm{TiO}_{2}\right.$-HA-rGO) by liquid flame spray deposition (Ref 100, 105). HA-enwrapped $\mathrm{TiO}_{2}$ nanocomposite powder was fabricated by using P25 particles as nucleation sites. HA in the composite powder acts as bait attracting approaching of bacteria and pushing them to $\mathrm{TiO}_{2}$. Moreover, the vacancies formed on the surface of excited phosphate group $\left(\mathrm{PO}_{4}^{3-}\right)$ in UV illumination might lead to formation of superoxide radical $\left(\mathrm{O}^{2-}\right)$, which also attacks the surrounding bacteria adsorbed on HA. As a result, the HA layer promoted significantly recruitment of $E$. coli bacteria onto the $\mathrm{TiO}_{2}$-based particles for subsequent photocatalytic killing, which gave rise to better capability of photocatalytic sterilization (Fig. 9).

\section{Thermal Spray Fabrication of Hollow Structured Photocatalysts}

The morphology of $\mathrm{TiO}_{2}$ particles influences their performance of photocatalytic viral disinfection. It is known that suspended reactors are more efficient than immobilized ones due to large surface area available for redox reactions. For instance, $\mathrm{TiO}_{2}$ hollow particles showed promoted photocatalytic performance than spherical ones in degradation of dimethyl sulfoxide due to the multi-scattering of light inside the hollow structure that could increase light absorption (Ref 106). However, the main drawback of using nano- or micro-sized particles in suspension is the necessity of post separation treatment or recycling of the catalyst, potentially making the use of the catalyst more complex and expensive.

To overcome the shortcoming of reusability of suspended reactors, researchers fabricated hollow microspheres of $\mathrm{TiO}_{2}$ that were easy to reuse. Ren et al. reported a suspension plasma sprayed hollow microsphere of $\mathrm{TiO}_{2}-$ $\mathrm{Fe}_{3} \mathrm{O}_{4}$ composites, exhibiting excelled photocatalytic performance and good reusability. Due to the presence of magnetic $\mathrm{Fe}_{3} \mathrm{O}_{4}$ nanoparticles in the $\mathrm{TiO}_{2}$ hollow spheres, the micro spheres can be easily recycled through external magnetic field (Fig. 10). Excellent photocatalytic sterilization performances were revealed for the $\mathrm{TiO}_{2}-\mathrm{Fe}_{3} \mathrm{O}_{4}$ hollow microspheres (Ref 107, 108). After 5 h UV irradiation, $\sim 99 \%$ bacteria were already exterminated. The addition of $\mathrm{Fe}_{3} \mathrm{O}_{4}$ did not deteriorate the photocatalytic performances of the $\mathrm{TiO}_{2}$ hollow spheres. Additionally, a special design of $\mathrm{FeO}_{x}-\mathrm{TiO}_{2}$ nano composites was proposed (Ref 109), which resolved the problem of reusability of the photocatalytic particles. According to the study of 

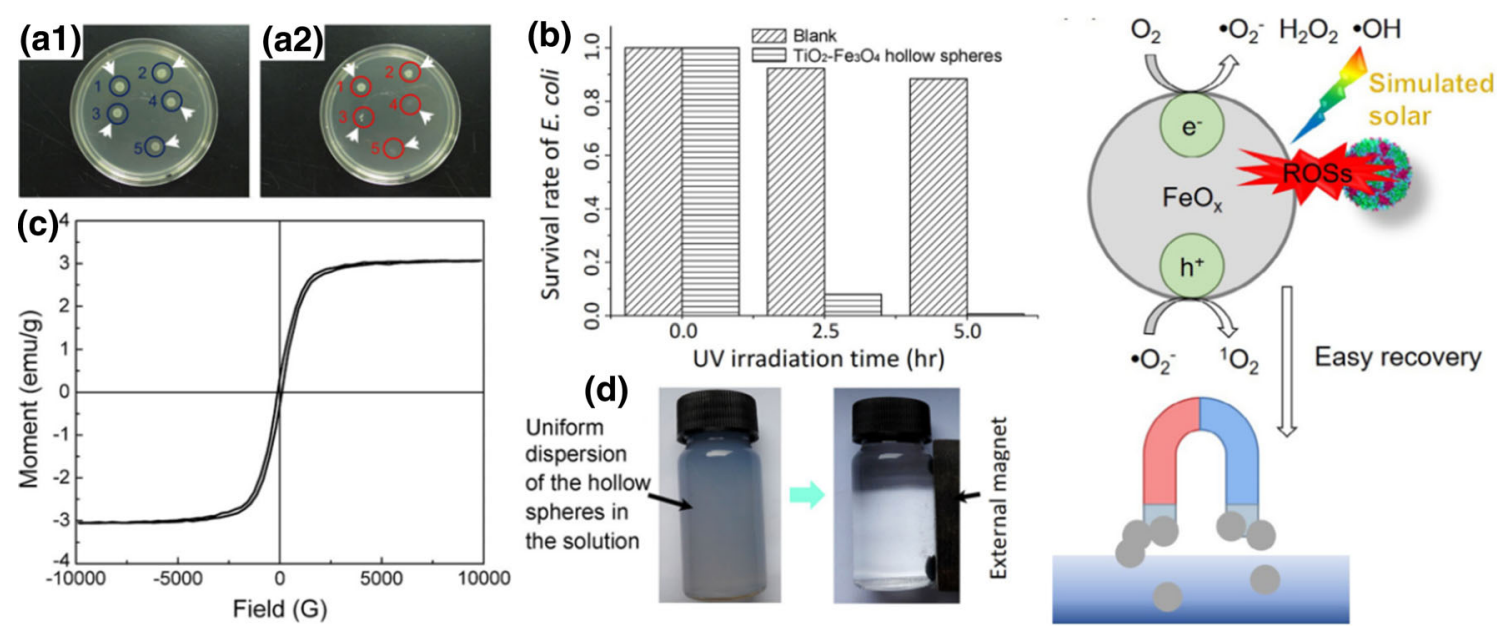

Fig. 10 Recyclable iron oxides-containing photocatalysts for bacterial (left) (Ref 107) and viral inactivation (right) (Ref 109)

Giannakis et al., three types of iron oxides (wüstite, maghemite, nano-maghemite) showed photocatalytic antiviral activity under solar irradiation (Fig. 10) (Ref 109). Particularly for wüstite, it exhibited the highest inactivation efficiency in both ultrapure water and wastewater, achieving 5- $\log \mathrm{MS}_{2}$ inactivation in $30 \mathrm{~min}$ and 2.6-log $\mathrm{MS}_{2}$ inactivation in $120 \mathrm{~min}$, respectively.

\section{Superhydrophobic Self-Cleaning Photocatalytic Coatings}

Self-cleaning surfaces have attracted attention due to their potential use in anti-bacteria and antifouling purposes (Ref $110,111)$. Photocatalyst coating with self-cleaning property combines dual functions of antibacterial effects: antiadhesive/self-cleaning surfaces and photocatalytic sterilization, which prevents the adherence of antibiotic-resistant bacteria and the formation of biofilms. Many researchers have reported various photocatalyst coatings constructed by using superhydrophobic or low energy surfaces, which can be used in a variety of fields including the reduction of HAIS (healthcare associated infections), marine antifouling, food industry, etc.

Self-cleaning photocatalyst coatings were fabricated by a number of techniques. According to $\mathrm{He}$ et al., a series of ZnO-rGO nanocomposite films were prepared by sol-gel technique. The ZnO-rGO films possess photocatalytic activity and photoinduced superhydrophilicity, and increased content of rGO enhanced both photocatalytic activity and photoinduced superhydrophilicity of the $\mathrm{ZnO}$ based films (Ref 112). For reduction of HAIS, Won et al. prepared $\mathrm{TiO}_{2}$-based transparent coatings as one such potential self-cleaning surface for touch screen application and evaluated their antimicrobial efficacy under dark and illuminated conditions (Ref 113). It was revealed that $\mathrm{n}-\mathrm{Ag} / \mathrm{TiO}_{2}(<100 \mathrm{~nm})$ coated samples achieved greater than $80 \%$ bactericidal efficacy with the lowest bacterial attachment after UV exposure (Ref 113).

To explore the industrial potential of the self-cleaning photocatalyst, researchers have recently attempted to develop hydrophobic/superhydrophobic surfaces by thermal spray processing. For instance, Teisala et al. developed a nanostructured $\mathrm{TiO}_{2}$ coating deposited on top of paperboard using liquid flame spray with a roll-to-roll setup at ambient pressure, which has potentials in using as selfcleaning surfaces (Ref 114). Valenzuela et al. prepared photoactive coatings using sol-gel $\mathrm{ZnO}$ suspensions through electro-spraying on glass substrates, and selfcleaning antimicrobial functions were reported (Ref 115). The electro-sprayed surfaces displayed antibacterial activity against Staphylococcus aureus with a reduction rate of over $99.5 \%$.

Because of the difficulty in constructing desired topographical nanostructures, insufficient hydrophobicity hinders the application of thermal spray in fabricating superhydrophobic coatings. An innovative method was proposed by Huang, et al. for plasma spray deposition of superhydrophobic coating by using $\mathrm{Al} @ \mathrm{WO}_{3}$ core-shell powder as the feedstock (Ref 116). Two nano-products $\left(\mathrm{Al}_{2} \mathrm{O}_{3}\right.$ and $\left.\mathrm{W}\right)$ were formed on the top layer of the coatings, as a result of transformation of $\mathrm{WO}_{3}$ to $\mathrm{W}$ during the spraying processing. They claimed that the acidic conditions facilitated the photocatalytic activity of the coatings. Co-existence of super hydrophobicity and photocatalytic performance suggests the potential antibacterial and antifouling applications of the thermal-sprayed coatings (Ref 116).

\section{Anti-biofilm Photocatalytic Coating}

Biofilm-related infections are predominately responsible for the spreading of many infectious diseases, particularly 
in the case of medical devices, foodborne diseases, and cause huge economic loss. Increased resistance to conventional antibiotics of pathogenic microbes requires the importance of developing alternative strategies for preventing pathogen dissemination. To construct anti-biofilm photocatalytic coatings, apart from the coating technique, understanding the mechanisms as to how surface characteristics of photocatalytic coatings influence the formation of the biofilms is essential.

A study by Jalvoa et al. on the influence of typical surface characteristics of $\mathrm{TiO}_{2}$-functionalized material on the formation of biofilms revealed that the biofilm-forming bacteria Staphylococcus aureus and Pseudomonas putida grew easily on $\mathrm{TiO}_{2}$-functionalized filters (Ref 117). The ROS products generated by the irradiation of visible-near UV light can kill all cells, while they were unable to remove the biofilm matrix formed during prior dark period. In a comparison study on bacterial cells death on 304 steel and $\mathrm{TiO}_{2}$ coatings conducted by McDonald et al. (Ref 118), it was revealed that $24 \%$ of the Pseudomonas aeruginosa bacterial cells on $\mathrm{HVOF}$ sprayed $\mathrm{TiO}_{2}$ coatings were killed after exposure to white light, comparing to merely about $6 \%$ on stainless steel surface. In contrast, Kikuchi et al. found that $\mathrm{TiO}_{2}$ thin films can kill $100 \%$ of E. coli bacteria after exposure to UV radiation (Ref 119). Therefore, McDonald et al. claimed that the difference is probably due to the ability of the Pseudomonas aeruginosa bacteria to form and embed themselves in biofilm matrix (Ref 118).

\section{Different Surface Topographies of $\mathrm{ZnO}$ Photocatalytic Coatings}

Topography of $\mathrm{ZnO}$ coatings influences their photocatalytic activities (Ref 120). To construct superior structure for modified electron band, Chen et al. made nano- $\mathrm{ZnO}$ coatings with porous topographical morphology through liquid plasma spraying. The coatings showed a porous skeleton and a fluffy top layer consisting of ultrafine $\mathrm{ZnO}$ grains, exhibiting a narrowed band gap and modified oxygen defects as compared to those deposited from single liquid feedstock (Ref 121). As reported by Heinonen, ZnO films with three topographies: needle-like hexagonal rods and flakes showed distinctive photocatalytic efficiency, which is proportional to their active surface area (Ref 122). Additionally, Rodríguez et al. used the spray pyrolysis (SP) technique to prepare different seed layers which plays a vital role in regulating crystalline growth and order of $\mathrm{ZnO}$ nanorods for the photocatalytic coatings (Ref 123). Higher surface area nanorods were preferentially synthesized in the samples prepared from the seed layer at $\mathrm{pH} 4$, which was considered to be the main parameter influencing the bacterial inactivation.
Finally, a comparison on the photocatalytic disinfection efficiency of thermal-sprayed photocatalytic coatings is summarized in Table 1.

\section{Photocatalytic Disinfection Mechanisms}

A variety of factors may influence the photocatalytic disinfection efficiency, including temperature, $\mathrm{pH}$ value of the aqueous solution, dissolved oxygen, light intensity, etc. Apart from the objective conditions, the inner mechanisms of photocatalysis are more important for the disinfection properties, including the roles of the photocatalysts in the disinfection process, and the response of pathogens to the catalysis at bio-molecular level. The exploration of the disinfection mechanisms will serve as a guidance to the design of photocatalysts for their large-scale industrial applications.

The disinfection mechanisms of different photocatalysts can be categorized into three aspects: physical damage to the cells by sharp edges of two-dimensional nano structural photocatalysts, toxicity of metal ions released from metalcontaining photocatalysts, chemical oxidation of reactive oxidative species (ROSs) and holes produced by photocatalysts. It is recognized that ROSs and holes generated from the photocatalytic process are primarily responsible for the disinfection property, especially against bacteria. As shown in Fig. 11, a schematic diagram of the mechanism of disinfection of bacteria is presented. The photocatalytic disinfection mainly relies on the photoexcitation of a semiconductor by the incident photons with the energy larger than its band gap energy level. In the photocatalytic disinfection process, electrons in the valence band (VB) get excited and move to the conduction band (CB), and photogenerated holes were left in the VB. Finally, photogenerated holes and electrons pairs are involved in redox reactions. Various reactive oxygen species (ROS) on the photocatalyst are formed, including $\cdot \mathrm{OH} \cdot \cdot \mathrm{HO}_{2}, \cdot \mathrm{O}_{2}{ }^{-}$, etc. It is recognized that hydroxyl radicals are majorly responsible for the disinfection property, especially against bacteria. Furthermore, other ROS species can attack the cell wall and cellular components, causing the oxidation of cellular components and membrane leakage (Ref 101). Either of these species attacks the phospholipid membrane of the cell wall and also the oxidation/reduction of the intracellular Co enzyme A, causing cell death and reduction in microbial population. Recently, enormous efforts have been made to study the photocatalytic disinfection mechanism and develop new photocatalysts, in order to acquire high efficiency in disinfection approaches for a wide range of pathogens, including bacteria, viruses, fungi, etc. 
Table 1 Summary of thermal-sprayed photocatalytic materials for biocidal applications

\begin{tabular}{|c|c|c|c|c|c|c|c|}
\hline \multirow[t]{2}{*}{ Different strategies } & \multirow[t]{2}{*}{ Materials } & \multirow[t]{2}{*}{ Microbe } & \multicolumn{2}{|c|}{ Operation condition } & \multicolumn{2}{|c|}{$\begin{array}{l}\text { Inactivation } \\
\text { efficiency }\end{array}$} & \multirow[t]{2}{*}{ References } \\
\hline & & & $\begin{array}{l}\text { Microbe level, } \\
\text { CFU/mL }\end{array}$ & Light source & $\begin{array}{l}\text { Time, } \\
\text { min }\end{array}$ & Reduction & \\
\hline \multirow{3}{*}{$\begin{array}{l}\text { Visible-light-induced } \\
\text { photocatalysis }\end{array}$} & $\mathrm{TiO}_{2}$ coating & E. coli & $10^{7}-10^{8}$ & Solar light & 70 & 4-log & Ref 80 \\
\hline & $\mathrm{TiO}_{2}-\mathrm{Cu}$ coating & P. aeruginosa & $10^{4}$ & Fluorescent lamp & 180 & $75 \%$ & Ref 82 \\
\hline & $\mathrm{TiO}_{2}-\mathrm{SrCO}_{3}$ coating & E. coli & $5 \times 10^{7}$ & Xe lamp & 240 & $99.7 \%$ & Ref 83 \\
\hline Black $\mathrm{TiO}_{2}$ & Black $\mathrm{TiO}_{2}$ powder & M. aeruginosa & $3 \times 10^{6}$ & Xe lamp & 720 & $99.09 \%$ & Ref 88 \\
\hline \multirow{5}{*}{$\begin{array}{l}\text { Porous photocatalytic } \\
\text { coating }\end{array}$} & $\mathrm{TiO}_{2}$ coating & Chlorella & $1.8 \times 10^{6}$ & UV lamp & 240 & $70.7 \%$ & Ref 98 \\
\hline & & P. micans & $4.7 \times 10^{4}$ & & 240 & $98.6 \%$ & \\
\hline & $\mathrm{TiO}_{2}$ coating & aeruginosa & $10^{4}-10^{8}$ & UV lamp & 5 & $>90 \%$ & Ref 99 \\
\hline & & S. aureus & $10^{4}-10^{8}$ & & $5-7$ & $>90 \%$ & \\
\hline & & C. albicans & $10^{3}-10^{5}$ & & 30 & $>90 \%$ & \\
\hline \multirow{3}{*}{$\begin{array}{l}\text { Recruit and kill } \\
\text { strategy }\end{array}$} & $\mathrm{TiO}_{2}$-HA-rGO coating & E. coli & $5 \times 10^{6}$ & UV lamp & 60 & $95 \%$ & Ref 100 \\
\hline & $\mathrm{TiO}_{2}-\mathrm{H} \beta$ Zeolite powder & E. coli & $10^{7}$ & UV lamp & 20 & $99 \%$ & Ref 101 \\
\hline & $\mathrm{TiO}_{2}$-HA powder & E. coli & $5 \times 10^{7}$ & UV lamp & 300 & $99 \%$ & Ref 104,105 \\
\hline $\begin{array}{l}\text { Hollow structured } \\
\text { photocatalysts }\end{array}$ & $\mathrm{TiO}_{2}-\mathrm{Fe}_{3} \mathrm{O}_{4}$ microspheres & E. coli & $5 \times 10^{7}$ & UV lamp & 300 & $99 \%$ & Ref 107,108 \\
\hline $\begin{array}{l}\text { Self-cleaning } \\
\text { photocatalytic } \\
\text { coatings }\end{array}$ & $\mathrm{ZnO}$ coating & S. aureus & $10^{8}$ & Simulated sunlight & 120 & $99.5 \%$ & Ref 115 \\
\hline Anti-biofilm & $\mathrm{TiO}_{2}$ coating & P. aeruginosa & $4.7 \times 10^{6}$ & White light & 120 & $24 \%$ & Ref 118 \\
\hline Topographies & $\mathrm{ZnO}$ coating & E. coli & $5 \times 10^{7}$ & Sunlight & 20 & $>99 \%$ & Ref 123 \\
\hline
\end{tabular}

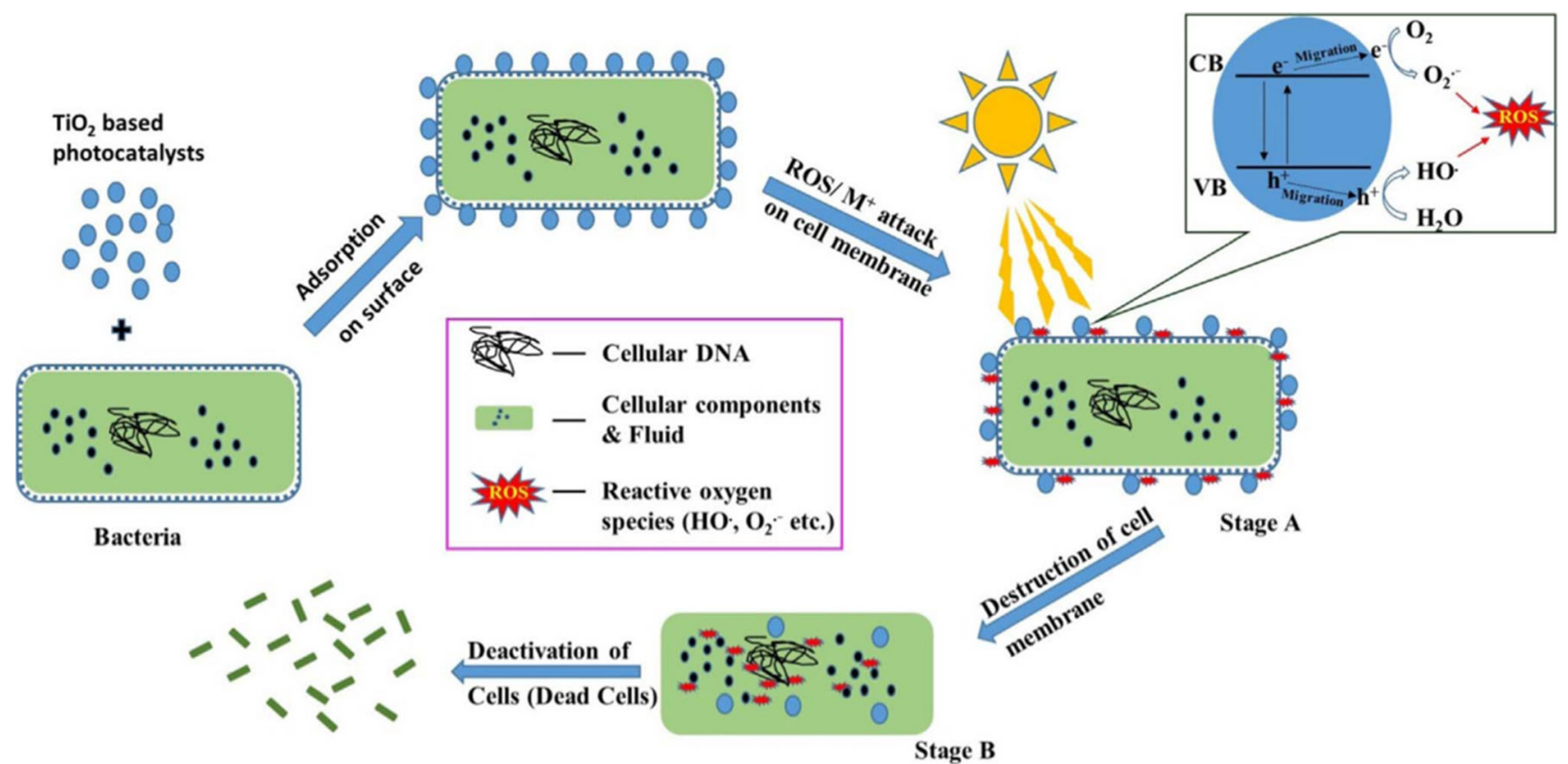

Fig. 11 The possible mechanisms of the photocatalytic disinfection of bacteria (Ref 101) 


\section{Photocatalytic Anti-bacteria Mechanisms}

Photocatalytic antibacterial properties are largely related to the bacterial structure. Schematic view of the difference in the antibacterial mechanisms for gram-positive and gramnegative bacteria is illustrated in Fig. 12 (Ref 124). Most bacteria can be classified as gram-positive and gram-negative groups. Their cell walls are made of a complex assembly of high molecular compounds (e.g., peptidoglycan polymers, teichoic acids, lipopolysaccharides, lipoproteins, phospholipids), which are the first surface target of photocatalysis. The outer membrane is absent for the gram-positive bacteria, and the peptidoglycan content of the two is different. Therefore, the primary targets of the gram-positive and gram-negative bacteria may vary, leading to different disinfection mechanisms for the two types of bacteria, where ROSs species with higher oxidation power and concentration are required for the inactivation of gram-positive bacteria because of the multilayered peptidoglycan. On the other hand, the damage effects caused by photocatalysis, including leakage of minerals, genetic material in the microbes, and peroxidation of lipids are common for both the bacteria. Therefore, the photocatalytic disinfections have broad-spectrum antibacterial property.

Among all kinds of microbes, bacteria are identified as an effective indicator for water pollution. E. coli is mostly studied among various bacteria and recognized as an indicator for water quality, since its presence generally reflects fecal contamination of water. Extensive studies have been carried out to evaluate various photocatalytic materials that are effective in disinfecting $E$. coli. The disinfection performances of $\mathrm{TiO}_{2}$ photocatalysis have been widely studied over the last two decades. To overcome the shortcomings of $\mathrm{TiO}_{2}$-based photocatalysts, recent research has been pertained to enhancing their photocatalytic inactivation efficiency.

Modification of crystal structure or doping of metals can be used to increase the photocatalytic efficiency by inhibiting photogenerated electron-hole recombination, or increasing visible-light absorption by forming impurity bands. For instance, Zheng et al. developed a one-dimensional photocatalyst from $\mathrm{Cu}-\mathrm{TiO}_{2}$ nanofibers, it has the advantages of high aspect ratio, large surface area, and limited aggregation (Ref 125, 126). Characterization of the photocatalyst demonstrated that $\mathrm{Cu}^{2+}$ substituted $\mathrm{Ti}^{4+}$ in the $\mathrm{TiO}_{2}$ lattice and formed an impurity energy level below the conduction band of $\mathrm{TiO}_{2}$, which enabled the nanofibers to realize visible-light response. According to Song et al., the surface modification of rutile phase nano $\mathrm{TiO}_{2}$ exhibited two times larger efficiency in $E$. coli disinfection than the unmodified material (Ref 127). Furthermore, it has also been shown that metal doping could enhance photocatalytic efficiency by formatting intermediate bands.

To further investigate the photocatalytic antibacterial mechanisms, Ji et al. studied the disinfection mechanism of a composite nanomaterial of $\mathrm{Bi}_{2} \mathrm{WO}_{6} / \mathrm{TiO}_{2} / \mathrm{rGO}$, by using E. coli as an indicator (Ref 52). Four scavengers, namely t-BuOH, $\mathrm{AO}, \mathrm{BQ}$, and $\mathrm{Cr}(\mathrm{VI})$, can be used to scavenge the radical species of $\mathrm{h}^{+}, \cdot \mathrm{OH}, \mathrm{e}^{-}$, and $\cdot \mathrm{O}^{2-}$, respectively. By intentionally adding different scavengers for comparison examination, the researchers claimed that the photoinduced $\mathrm{h}^{+}$played a vital role in the disinfection process, while $\cdot \mathrm{OH}, \mathrm{e}^{-}$, and $\cdot \mathrm{O}^{2-}$ exhibited synergistic effects.
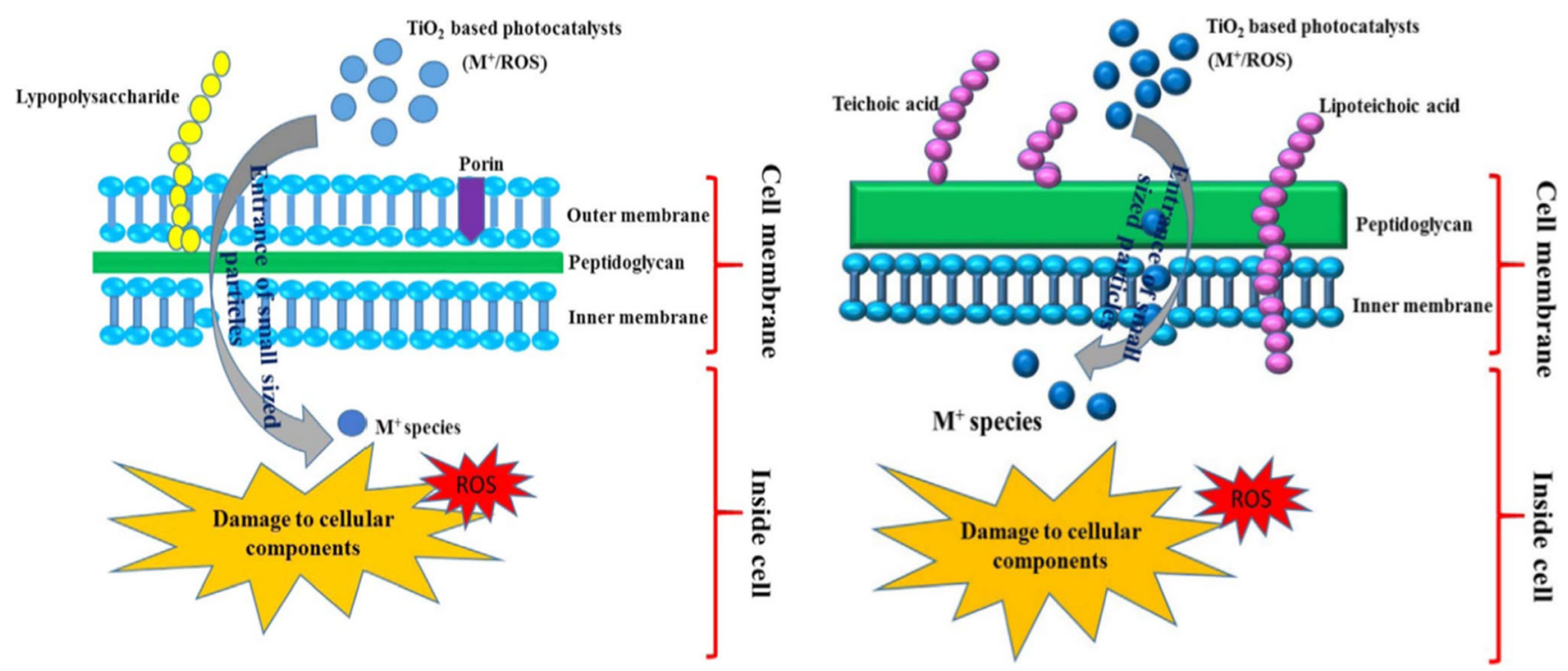

Fig. 12 Differences in membrane structural composition and proposed antibacterial mechanism for the gram-negative bacteria (left) and the gram-positive bacteria (right) (Ref 124) 


\section{Photocatalytic Anti-virus Mechanisms}

There is a vast variety of viruses, which show a different resistance to inactivation in photocatalysis due to different sizes, shapes, structures or compositions. As shown in Fig. 13, the viruses can be classified into two categories, RNA-type and DNA-type viruses, which usually consist of genetic gene (RNA or DNA) and protein shell (capsid). Viral inactivation is mainly related to physical damage, metal toxicity, or ROS species (e.g., $\cdot \mathrm{OH})$. It must be noted that, unlike the anti-bacteria process, viral disinfection involves denaturation of the rigid protein shell, requiring much more oxidizing power. Based on the current research in the field of photocatalytic viral disinfection, the inactivation falls into three steps: (1) particle shape distortion, (2) protein oxidation, and (3) gene leakage or damage. According to Ishiguro et al., RNA phage $\mathrm{Q} \beta$ and DNA phage $\mathrm{T} 4$ exhibited a different resistance in a $\mathrm{TiO}_{2}-\mathrm{UV}$ system, where the inactivation of $\mathrm{Q} \beta$ was more rapid than that of T4, suggesting the virus gene type influences photocatalytic inactivation kinetics (Ref 128).

The physical damage effect can be evidenced by the comparison study on the viral inactivation ability of graphene oxide (GO) and GO-aptamer-based photocatalysts. Physical damage in viral disinfection is typically involved in graphene-based photocatalysis, for which graphene with many sharp edges cut through protein shells of viruses and inactivated them. It was noted that the bare GO exhibited a similar viricidal activity in dark as that in light (Ref 56). As a comparison, the GO-aptamer with blunt edges posed less viral inactivation than that of the bare GO with sharp edges, confirming that sharp edges of GO played an important role for inactivating viruses physically.

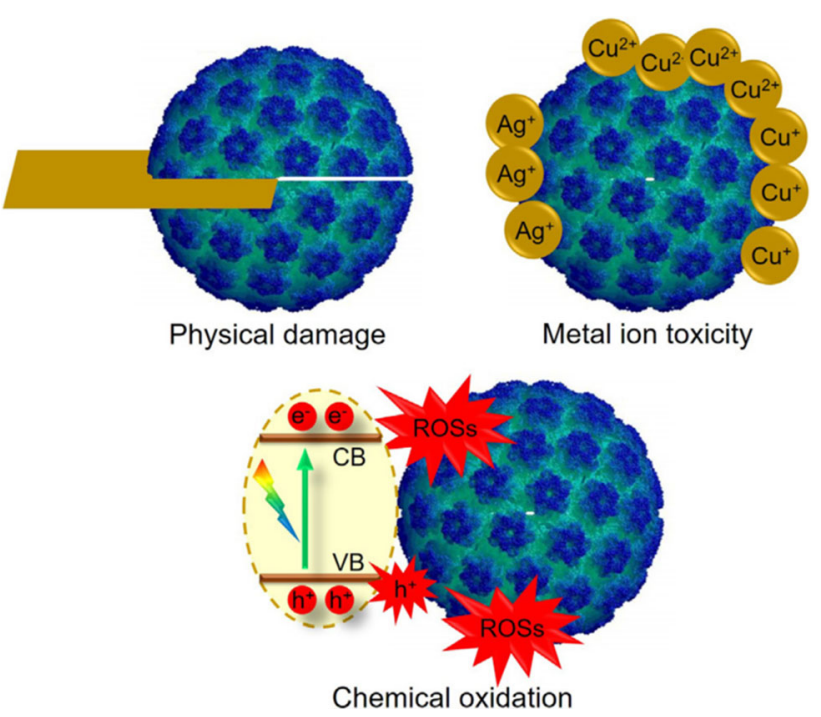

Fig. 13 Three major mechanisms of viral disinfection induced by photocatalysts (Ref 20)
Considering the metal toxicity, it was revealed that combination of photocatalysis and toxicity of metal ions works synergistically to enhance the disinfection effect. Ditta et al. reported that $\mathrm{TiO}_{2} / \mathrm{CuO}$ films showed faster viral inactivation kinetics than undoped films, although low photoactivity was observed, confirming a major antibacterial and antiviral contribution of released toxic $\mathrm{Cu}$ ions (Ref 129). In contrast, there is little to no viral inactivation in the solution containing $\mathrm{Ag}^{+}$, of which the concentration was equivalent to that released from $\mathrm{Ag} / \mathrm{TiO}_{2}$ under $\mathrm{UV}$ irradiation, suggesting a minor viral disinfection contribution of $\mathrm{Ag}^{+}$(Ref 130).

As to the ROS factors, according to the investigation conducted by Zhang (Ref 131), although the estimated concentration of $\cdot \mathrm{OH}$ was several orders of magnitude lower than that of $\mathrm{O}^{2-}$ in $\mathrm{g}-\mathrm{C}_{3} \mathrm{~N}_{4}$-based disinfection system, $\cdot \mathrm{OH}$ is still believed to play a critical role in viral inactivation with higher oxidizing power. Hence, $\cdot \mathrm{OH}$ with a more positive reduction potential than $\cdot \mathrm{O}^{2-}$ could enable the denaturation process. Furthermore, Horovitz et al. found the difficulty in inactivation of the tested microorganisms is in the order E. coli $<M S_{2}<$ Aspergillus niger (Ref 132). The photocatalytic disinfection testing indicates that the viruses $\left(M S_{2}\right.$ phage $)$ were inactivated mainly by the free hydroxyl radicals in the solution, while $E$. coli is inactivated by both the free and the surface-bound hydroxyl radicals and other ROS, such as $\mathrm{O}_{2}^{-}$and $\mathrm{H}_{2} \mathrm{O}_{2}$.

\section{Photocatalytic Anti-fungi Mechanisms}

The occurrences of pathogenic fungi in daily use water arose increased attention, which posed a potential threat to human health and agriculture production. A couple of published works studied the photocatalytic activity of $\mathrm{TiO}_{2}$ on disinfection of fungi. The denaturation of the cell wall of fungi is a major aspect for its disinfection. It is believed that the rigid cell wall of fungus acts as a major obstacle, which requires ROSs with high oxidizing power (e.g., . $\mathrm{OH})$. As illustrated in Fig. 14, the nanoparticle generates hydroxyl radicals $(\cdot \mathrm{OH})$ under visible-light illumination, which directly apply to the surface of fungal cell wall. This radical reacts with glucan and chitin layers of fungal cell wall that results in cell wall degradation and subsequent cell death.

Disinfection of fungi by $\mathrm{TiO}_{2}$-based nanomaterials has been reported. Zhang et al. developed a novel method for synthesis of $\mathrm{TiO}_{2}$ photocatalyst with copper modification and $\mathrm{Ti}^{3+}$-doping, and it exhibited broad-spectrum antifungal performances (Ref 133). The work also revealed that the damage of spore walls/membranes of the fungal spores was increased by the photocatalysis, suggesting photo-disinfection mechanism. In another study, disinfection of Fusarium oxysporum fungal was realized by $\mathrm{TiO}_{2}$ 


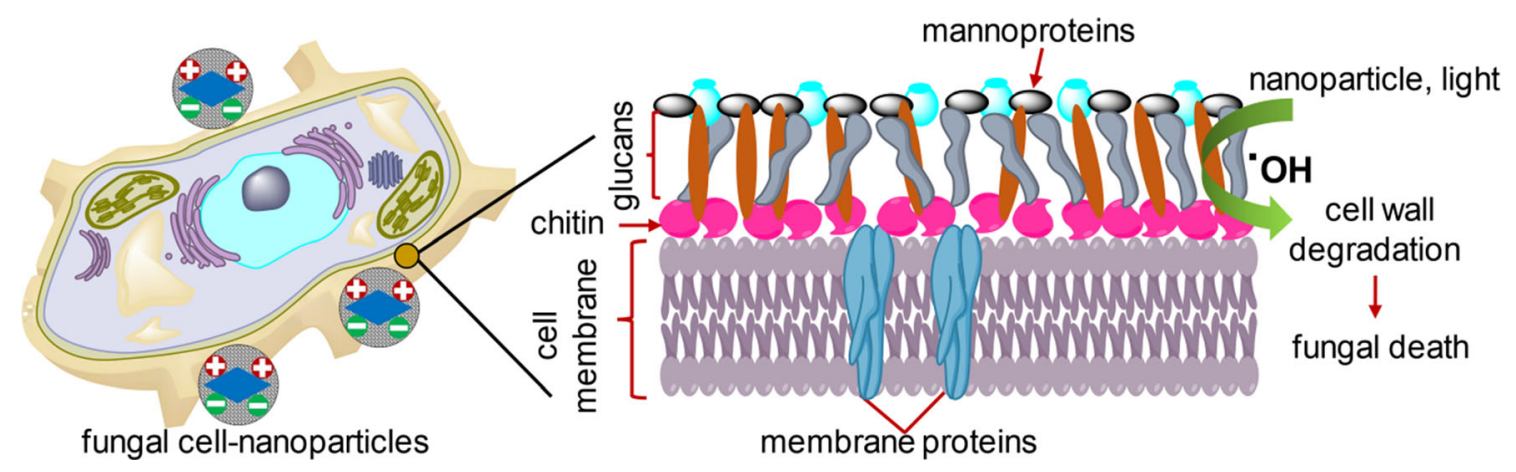

Fig. 14 Proposed mechanism of antifungal activity of $\mathrm{N}, \mathrm{F}$ co-doped $\mathrm{TiO}_{2}$ nanoparticle (Ref 124)

nanoparticles co-doped with $\mathrm{N}$ and $\mathrm{F}$ exposed under visible light. El-Sayyad et al. reported a gamma-irradiated nanocomposite $\mathrm{Co}_{\mathrm{x}} \mathrm{Ni}_{1-\mathrm{x}} \mathrm{Fe}_{2} \mathrm{O}_{4} / \mathrm{SiO}_{2} / \mathrm{TiO}_{2} x=0.9$ which shows promising antifungal abilities (Ref 134). All these works showed efficient interaction of photocatalytic nanoparticles with the fungal cell wall and visible-lightinduced ROS products give rise to the fungal disinfection.

\section{Conclusions and Future Perspectives}

Aimed at the emerging demands for disinfection of pathogenic microbes, many photocatalytic materials have been developed by using different processing routes recently. In this critical review, we have summarized the research works about the typical photocatalytic materials, their biocidal performance, and mechanisms. The thermal spray technique, as a most promising way in fabricating large-scale photocatalytic coatings, has also been reviewed in different trends. Tremendous achievements have been accomplished in this field during the past years, yet it should be pointed out that there still remain a number of challenges, while some of the problems still need to be tackled for further study.

The large-scale preparation and the immobilization of nanomaterial photocatalysts are two key problems for practical applications. Among various surface modification routes, thermal spray method perfectly solves the above problems due to offering a facile one-step fabrication route in realizing large-scale photocatalytic coatings and synthesizing immobilized photocatalytic coatings on desirable solid surfaces for practical use. Through element doping, structure construction, and chemical synthesis during the spraying process, a number of photocatalytic disinfection purposes can be realized by using thermal spray method, including visible-light-induced sterilization, self-cleaning anti-biofouling surface, etc. Black $\mathrm{TiO}_{2}$ and porous structured antimicrobial photocatalytic coatings are realized by using thermal spray methods to enhance the efficiency in disinfection. Recruitment and killing strategies are realized by employing thermal spraying and seeking answers in nature.

All in all, thermal spraying method perfectly integrated the novel structural and functional properties in fabricating photocatalytic coatings. However, though a number of studies about the antibacterial application of thermalsprayed coating were launched, the studies of thermalsprayed photocatalytic materials and related disinfection mechanisms for anti-virus and anti-fungus applications are still rare. Development of new wide-spectrum and high efficiency photocatalytic materials, theoretical data and inactive mechanisms, and expanding applications for antiviral and anti-fungi purposes still need to explore. With ever-increasing number of scientists focused on this area, we believe that the goals in enhancing the performance and exploring practical use in versatile environments can be achieved in the future.

Acknowledgments This research was supported by National Natural Science Foundation of China (Grant \# 52071329), Zhejiang Provincial Natural Science Foundation of China (Grant \# LY18C100003), the Youth Innovation Promotion Association of the Chinese Academy of Sciences, China (Grant \# 2020299), and Innovation 2025 Major Special Programme of Ningbo, China.

\section{References}

1. J. Kaur, R. Karthikeyan, and R. Smith, Assessment of Escherichia coli Reactivation After Photocatalytic Water Disinfection Using Flow Cytometry: Comparison with a Culture-Based Method, Water Sci. Technol. Water Supply, 2013, 13(3), p 816825

2. S. Saran, P. Arunkumar, and S.P. Devipriya, Disinfection of Roof Harvested Rainwater for Potable Purpose Using PilotScale Solar Photocatalytic Fixed Bed Tubular Reactor, Water Sci Technol Water Supply, 2018, 18(1), p 49-59

3. J.H. Castillo-Ledezma, J.L.S. Salas, A. Lopez-Malo, and E.R. Bandala, Effect of $\mathrm{pH}$, Solar Irradiation, and Semiconductor Concentration on the Photocatalytic Disinfection of Escherichia coli in Water Using Nitrogen-Doped $\mathrm{TiO}_{2}$, Eur. Food Res. Technol., 2011, 233(5), p 825-834 
4. K. Pietrzak and B. Gutarowska, The Effectiveness of Photocatalytic Ionisation Disinfection of Filter Materials, Pol. J. Microbiol., 2013, 62(2), p 131-139

5. A.Y. Booshehri, R. Wang, and R. Xu, Fabrication of a Catalytic Polymer Composite Sheet Enabling Visible Light-Driven Photocatalytic Disinfection of Water, Res. Chem. Intermed., 2016, 42(5), p 4827-4838

6. A. Iftikhar, M.S. Khan, U. Rashid, Q. Mahmood, H. Zafar, M. Bilal, and N. Riaz, Influence of Metallic Species for Efficient Photocatalytic Water Disinfection: Bactericidal Mechanism of In Vitro Results Using Docking Simulation, Environ. Sci. Pollut. Res., 2020, https://doi.org/10.1007/s11356-020-08974-Z

7. H.T. Yu, S. Chen, X. Quan, and Z.H. Zhang, The Mechanism, Materials and Reactors of Photocatalytic Disinfection in Water and Wastewater Treatment, Prog. Chem., 2017, 29(9), p 10301041

8. P. Murugesan, J.A. Moses, and C. Anandharamakrishnan, Photocatalytic Disinfection Efficiency of 2D Structure Graphitic Carbon Nitride-Based Nanocomposites: A Review, J. Mater. Sci., 2019, 54(19), p 12206-12235

9. J. Gamage and Z.S. Zhang, Applications of Photocatalytic Disinfection, Int. J. Photoenergy, 2010, 2010, p 764870-764880

10. K. Watson, G. Shaw, F.D.L. Leusch, and N.L. Knight, Chlorine Disinfection by-Products in Wastewater Effluent: BioassayBased Assessment of Toxicological Impact, Water Res., 2012, 46(18), p 6069-6083

11. R.E. Selleck, B.M. Saunier, and H.F. Collins, Kinetics of Bacterial Deactivation with Chlorine, J. Environ. Eng. ASCE, 1978, 104(6), p 1197-1212

12. C.A. Castro, A. Jurado, D. Sissa, and S.A. Giraldo, Performance of Ag- $\mathrm{TiO}_{2}$ Photocatalysts Towards the Photocatalytic Disinfection of Water Under Interior-Lighting and Solar-Simulated Light Irradiations, Int. J. Photoenergy, 2012, 2012, p 261045261055

13. A. Kubacka, M. Ferrer, and M. Fernandez-Garcia, Kinetics of Photocatalytic Disinfection in $\mathrm{TiO}_{2}$-Containing Polymer Thin films: UV and Visible Light Performances, Appl. Catal. B Environ., 2012, 121, p 230-238

14. N. Kaneva, I. Stambolova, V. Blaskov, Y. Dimitriev, A. Bojinova, and C. Dushkin, A Comparative Study on the Photocatalytic Efficiency of ZnO Thin Films Prepared by Spray Pyrolysis and Sol-Gel Method, Surf. Coat. Technol., 2012, 207, p 5-10

15. Y.M. Hunge, M.A. Mahadik, V.S. Mohite, S.S. Kumbhar, N.G. Deshpande, K.Y. Rajpure, A.V. Moholkar, P.S. Patil, and C.H. Bhosale, Photoelectrocatalytic Degradation of Methyl Blue Using Sprayed $\mathrm{WO}_{3}$ Thin Films, J. Mater. Sci. Mater. Electron., 2016, 27(2), p 1629-1635

16. C. Zhang, Y. Li, D. Shuai, Y. Shen, W. Xiong, and L. Wang, Graphitic Carbon Nitride $\left(\mathrm{g}-\mathrm{C}_{3} \mathrm{~N}_{4}\right)$-Based Photocatalysts for Water Disinfection and Microbial Control: A Review, Chemosphere, 2019, 214, p 462-479

17. B. Reti, Z. Major, D. Szarka, T. Boldizsar, E. Horvath, A. Magrez, L. Forro, A. Dombi, and K. Hernadi, Influence of $\mathrm{TiO}_{2}$ Phase Composition on the Photocatalytic Activity of $\mathrm{TiO}_{2} /$ MWCNT Composites Prepared by Combined Sol-Gel/Hydrothermal METHOD, J. Mol. Catal. A Chem., 2016, 414, p 140-147

18. M. Khraisheh, L.J. Wu, A.H. Al-Muhtaseb, and M.A. AlGhouti, Photocatalytic Disinfection of Escherichia coli Using $\mathrm{TiO}_{2} \mathrm{P} 25$ and $\mathrm{Cu}-$ Doped $\mathrm{TiO}_{2}$, J. Ind. Eng. Chem., 2015, 28, p 369-376

19. C. Sordo, R. Van Grieken, J. Marugan, and P. Fernandez-Ibanez, Solar Photocatalytic Disinfection with Immobilised $\mathrm{TiO}_{2}$ at Pilot-Plant Scale, Water Sci. Technol., 2010, 61(2), p 507-512

20. C. Zhang, Y. Li, D.M. Shuai, Y. Shen, and D.W. Wang, Progress and Challenges in Photocatalytic Disinfection of
Waterborne Viruses: A Review to Fill Current Knowledge Gaps, Chem. Eng. J., 2019, 355, p 399-415

21. M. Zhai, Y. Liu, J. Huang, Y. Wang, K. Chen, Y. Fu, and H. Li, Efficient Suspension Plasma Spray fabrication of Black titanium Dioxide Coatings with Visible Light Absorption Performances, Ceram. Int., 2019, 45(1), p 930-935

22. C. Karunakaran, A. Vijayabalan, G. Manikandan, and P. Gomathisankar, Visible Light Photocatalytic Disinfection of Bacteria by $\mathrm{Cd}-\mathrm{TiO}_{2}$, Catal. Commun., 2011, 12(9), p 826-829

23. Y.C. Yan, X.Q. Zhou, J.R. Lan, Z.F. Li, T.L. Zheng, W.B. Cao, N. Zhu, and W.X. Liu, Efficient Photocatalytic Disinfection of Escherichia coli by N-Doped $\mathrm{TiO}_{2}$ Coated on Coal Fly Ash Cenospheres, J. Photochem. Photobiol. A, 2018, 367, p 355-364

24. C. Pablos, J. Marugan, R. van Grieken, P.S.M. Dunlop, J.W.J. Hamilton, D.D. Dionysiou, and J.A. Byrne, Electrochemical Enhancement of Photocatalytic Disinfection on Aligned $\mathrm{TiO}_{2}$ and Nitrogen Doped $\mathrm{TiO}_{2}$ Nanotubes, Molecules, 2017, 22(5), p 1-15

25. L. Liu, Z.Y. Liu, H.W. Bai, and D.D. Sun, Concurrent Filtration and Solar Photocatalytic Disinfection/Degradation Using HighPerformance $\mathrm{Ag} / \mathrm{TiO}_{2}$ Nanofiber Membrane, Water Res., 2012, 46(4), p 1101-1112

26. Y. Shimizu, M. Ateia, M.N. Wang, D. Awfa, and C. Yoshimura, Disinfection Mechanism of E. coli by $\mathrm{CNT}-\mathrm{TiO}_{2}$ Composites: Photocatalytic Inactivation vs. Physical Separation, Chemosphere, 2019, 235, p 1041-1049

27. M. Long, G. Zhan, M.Y. Sun, H. Zhuang, and R. Wang, Physical Properties of $\mathrm{Fe}^{3+} / \mathrm{TiO}_{2}$ Nanoparticles and Photocatalytic Disinfection of Foodborne Microorganisms, Curr. Top. Nutraceut. Res., 2019, 17(3), p 312-321

28. C. Berberidou, G.Z. Kyzas, I. Paspaltsis, T. Sklaviadis, and I. Poulios, Photocatalytic Disinfection and Purification of Water Employing Reduced Graphene Oxide/ $/ \mathrm{TiO}_{2}$ Composites, $J$. Chem. Technol. Biotechnol., 2019, 94(12), p 3905-3914

29. H. Younas, I.A. Qazi, I. Hashmi, M.A. Awan, A. Mahmood, and H.A. Qayyum, Visible Light Photocatalytic Water Disinfection and Its Kinetics Using Ag-Doped Titania Nanoparticles, Environ. Sci. Pollut. Res., 2014, 21(1), p 740-752

30. G. Pedroza-Herrera, I.E. Medina-Ramirez, J.A. Lozano-Alvarez, and S.E. Rodil, Evaluation of the Photocatalytic Activity of Copper Doped $\mathrm{TiO}_{2}$ Nanoparticles for the Purification and/or Disinfection of Industrial Effluents, Catal. Today, 2020, 341, p $37-48$

31. N. Janpetch, C. Vanichvattanadecha, and R. Rujiravanit, Photocatalytic Disinfection of Water by Bacterial Cellulose/N-F Codoped $\mathrm{TiO}_{2}$ Under Fluorescent Light, Cellulose, 2015, 22(5), p 3321-3335

32. L.L. Lai and J.M. Wu, A Facile Solution Approach to W, N Codoped $\mathrm{TiO}_{2}$ Nanobelt Thin Films with High Photocatalytic Activity, J. Mater. Chem. A, 2015, 3(31), p 15863-15868

33. R. Leary and A. Westwood, Carbonaceous Nanomaterials for the Enhancement of $\mathrm{TiO}_{2}$ Photocatalysis, Carbon, 2011, 49(3), p $741-772$

34. Y. Fu, Y. Liu, and H. Li, Onion-Like Carbon-Modified $\mathrm{TiO}_{2}$ Coating by Suspension Plasma Spray with Enhanced PHOTOCATALYTIC Performances, J. Nanopart. Res., 2019, 21(8), p 1-12

35. O. Akhavan, M. Mehrabian, K. Mirabbaszadeh, and R. Azimirad, Hydrothermal Synthesis of ZnO Nanorod Arrays for Photocatalytic Inactivation of Bacteria, J. Phys. D Appl., 2009, 42(22), p 225305-225314

36. W. Jiang, T. Huang Fu, X. Yang, L. Bao, Y. Liu, G. Xu, and G. Han, Surfactant-Free Hydrothermal Synthesis of Hierarchical Flower-Like $\mathrm{Bi}_{2} \mathrm{WO}_{6}$ Mesosphere Nanostructures with Excellent Visible-Light Photocatalytic Activity, CrystEngComm, 2019, 21(41), p 6293-6300 
37. Y.M. Hunge, Sunlight Assisted Photoelectrocatalytic Degradation of Benzoic Acid Using Stratified $\mathrm{WO}_{3} / \mathrm{TiO}_{2}$ Thin Films, Ceram. Int., 2017, 43(13), p 10089-10096

38. T. Yan, J. Huang, J. Bi, L. Xie, and H. Huang, Preparation of $\mathrm{Ga}_{0.25} \mathrm{Zn}_{4.67} \mathrm{~S}_{5.08}$ Microsphere by Ultrasonic Spray Pyrolysis and Its Photocatalytic Disinfection Performance Under Visible Light, J. Nanomater., 2019, 2019, p 9151979

39. S. Wojtyla, W. Macyk, and T. Baran, Photosensitization of CuI-The Role of Visible Light Induced Cu-I, -> Cu-II, Transition in Photocatalytic Degradation of Organic Pollutants and Inactivation of Microorganisms, Photochem. Photobiol. Sci., 2017, 16(7), p 1079-1087

40. R.M. Trommer, A.K. Alves, and C.P. Bergmann, Synthesis, Characterization and Photocatalytic Property of Flame Sprayed Zinc Oxide Nanoparticles, J. Alloys Compd., 2010, 491, p 296300

41. J. Alarcón, S. Ponce, F. Paraguay-Delgado, and J. Rodríguez, Effect of Gamma-Irradiation on the Growth of $\mathrm{ZnO}$ Nanorod Films for Photocatalytic Disinfection of Contaminated Water, $J$. Colloids Interface Sci., 2011, 364(1), p 49-55

42. L. Sanchez, L. Guz, P. Garcia, S. Ponce, S. Goyanes, M.C. Marchi, R. Candal, W. Estrada, and J. Rodriguez, Influence of Pyrolytic Seeds on $\mathrm{ZnO}$ Nanorod Growth onto Rigid Substrates for Photocatalytic Abatement of Escherichia coli in Water, Water Sci. Technol. Water Supply, 2014, 14(6), p 1087-1094

43. L. Sanchez, L. Guz, P. Garcia, S. Ponce, S. Goyanes, M. Claudia Marchi, R. Candal, and J. Rodriguez, Synthesis and Characterization of ZnO Nanorod Films on PET for Photocatalytic Disinfection of Water, J. Adv. Oxid. Technol., 2015, 18(2), p 246252

44. B. Najma, A.K. Kasi, J.K. Kasi, A. Akbar, S.M.A. Bokhari, and I.R.C. Stroe, ZnO/AAO Photocatalytic Membranes for Efficient Water Disinfection: Synthesis, Characterization and Antibacterial Assay, Appl. Surf. Sci., 2018, 448, p 104-114

45. A.J. Misra, S. Das, A.P.H. Rahman, B. Das, R. Jayabalan, S.K. Behera, M. Suar, A.J. Tamhankar, A. Mishra, C.S. Lundborg, and S.K. Tripathy, Doped $\mathrm{ZnO}$ Nanoparticles Impregnated on Kaolinite (Clay): A Reusable Nanocomposite for Photocatalytic Disinfection of Multidrug Resistant Enterobacter sp. Under Visible Light, J. Colloids Interface Sci., 2018, 530, p 610-623

46. Z.Z. Li, X.C. Meng, and Z.S. Zhang, Hexagonal SnS Nanoplates Assembled onto Hierarchical $\mathrm{Bi}_{2} \mathrm{WO}_{6}$ with Enhanced Photocatalytic Activity in Detoxification and Disinfection, J. Colloids Interface Sci., 2019, 537, p 345-357

47. Z.O. Alafif, M. Anjum, M.O. Ansari, R. Kumar, J. Rashid, M. Madkour, and M.A. Barakat, Synthesis and Characterization of S-Doped-rGO/ZnS Nanocomposite for the Photocatalytic Degradation of 2-Chlorophenol and Disinfection of Real Dairy Wastewater, J. Photochem. Photobiol. A, 2019, 377, p 190-197

48. P. Chandran, P. Kumari, and S.S. Khan, Photocatalytic Activation of CdS NPs Under Visible Light for Environmental Cleanup and Disinfection, Sol. Energy, 2014, 105, p 542-547

49. K. Takehara, K. Yamazaki, M. Miyazaki, Y. Yamada, S. Ruenphet, A. Jahangir, D. Shoham, M. Okamura, and M. Nakamura, Inactivation of Avian Influenza Virus HIM by Photocatalyst Under Visible Light Irradiation, Virus Res., 2010, 151(1), p 102-103

50. O. Akhavan, M. Choobtashani, and E. Ghaderi, Protein Degradation and RNA Efflux of Viruses Photocatalyzed by GrapheneTungsten Oxide Composite Under Visible Light Irradiation, $J$. Phys. Chem. C, 2012, 116(17), p 9653-9659

51. Y.N. Jia, S.H. Zhan, S.L. Ma, and Q.X. Zhou, Fabrication of $\mathrm{TiO}_{2}-\mathrm{Bi}_{2} \mathrm{WO}_{6}$ Binanosheet for Enhanced Solar Photocatalytic Disinfection of E coli: Insights on the Mecanism, ACS Appl. Mater. Interfaces, 2016, 8(11), p 6841-6851
52. L. Ji, B. Liu, Y. Qian, Q. Yang, and P. Gao, Enhanced VisibleLight-Induced Photocatalytic Disinfection of Escherichia coli by Ternary $\mathrm{Bi}_{2} \mathrm{WO}_{6} / \mathrm{TiO}_{2} /$ Reduced Graphene Oxide Composite Materials: Insight into the Underlying Mechanism, Adv. Powder Technol., 2020, 31(1), p 128-138

53. Y. Li, J. Zhao, G.S. Zhang, L.L. Zhang, S.Y. Ding, E.X. Shang, and X.H. Xia, Visible-Light-Driven Photocatalytic Disinfection Mechanism of $\mathrm{Pb}_{-}-\mathrm{BiFeO}_{3} / \mathrm{rGO}$ Photocatalyst, Water Res., 2019, 161(10), p 251-261

54. P. Gao, J.C. Liu, D.D. Sun, and W. Ng, Graphene Oxide-CdS Composite with High Photocatalytic Degradation and Disinfection Activities Under Visible Light Irradiation, J. Hazard. Mater., 2013, 250, p 412-420

55. X.M. Song, J.M. Wu, L. Meng, and M. Yan, Enhanced Light Response of Titania Nanotube Arrays Sensitized with Pyrite $\mathrm{FeS}_{2}$, J. Am. Chem. Soc., 2010, 93(7), p 2068-2073

56. K.J. Moor and J.H. Kim, Simple Synthetic Method Toward Solid Supported C-60 Visible Light-Activated Photocatalysts, Environ. Sci. Technol., 2014, 48(5), p 2785-2791

57. J. Lee, Y. Mackeyev, M. Cho, D. Li, J.H. Kim, L.J. Wilson, and P.J.J. Alvarez, Photochemical and Antimicrobial Properties of Novel C-60 Derivatives in Aqueous Systems, Environ. Sci. Technol., 2009, 43(17), p 6604-6610

58. M. Cho, J. Lee, Y. Mackeyev, L.J. Wilson, P.J.J. Alvarez, J.B. Hughes, and J.H. Kim, Visible Light Sensitized Inactivation of MS-2 Bacteriophage by a Cationic Amine-Functionalized C-60 Derivative, Environ. Sci. Technol., 2010, 44(17), p 6685-6691

59. J. Lee, Y. Mackeyev, M. Cho, L.J. Wilson, J.H. Kim, and P.J.J. Alvarez, C-60 Aminofullerene Immobilized on Silica as a Visible-Light-Activated Photocatalyst, Environ. Sci. Technol., 2010, 44(24), p 9488-9495

60. K.J. Moor, D.C. Valle, C. Li, and J.H. Kim, Improving the Visible Light Photoactivity of Supported Fullerene Photocatalysts Through the Use of C-70 Fullerene, Environ. Sci. Technol., 2015, 49(10), p 6190-6197

61. X.G. Hu, L. Mu, J.P. Wen, and Q.X. Zhou, Covalently Synthesized Graphene Oxide-Aptamer Nanosheets for Efficient Visible-Light Photocatalysis of Nucleic Acids and Proteins of Viruses, Carbon, 2012, 50(8), p 2772-2781

62. C. Zhang, Y. Li, D.M. Shuai, W.L. Zhang, L.H. Niu, L.F. Wang, and H.J. Zhan, Visible-Light-Driven, Water-Surface-Floating Antimicrobials Developed it from Graphitic Carbon Nitride and Expanded Perlite for Water Disinfection, Chemosphere, 2018, 208, p 84-92

63. Y. Liu, X.K. Zeng, X.Y. Hu, J. Hu, and X.W. Zhang, TwoDimensional Nanomaterials for Photocatalytic Water Disinfection: Recent Progress and Future Challenges, J. Chem. Technol. Biotechnol., 2018, 94(1), p 22-37

64. J. Xu, Z.P. Wang, and Y.F. Zhu, Enhanced Visible-Light-Driven Photocatalytic Disinfection Performance and Organic Pollutant Degradation Activity of Porous g- $\mathrm{C}_{3} \mathrm{~N}_{4}$ Nanosheets, ACS Appl. Mater. Interfaces, 2017, 9(33), p 27727-27735

65. S. Ma, S. Zhan, Y. Jia, and Q. Zhou, Superior Antibacterial Activity of $\mathrm{Fe}_{3} \mathrm{O}_{4}-\mathrm{TiO}_{2}$ Nanosheets Under Solar Light, ACS Appl. Mater. Interfaces, 2015, 7(39), p 21875-21883

66. G. Wang, Z. Xing, X.K. Zeng, C.P. Feng, D.T. McCarthy, A. Deletic, and X.W. Zhang, Ultrathin Titanium Oxide Nanosheets Film with Memory Bactericidal Activity, Nanoscale, 2016, 8(42), p 18050-18056

67. Q.J. Zhang, C.H. Sun, Y. Zhao, S.Y. Zhou, X.J. Hu, and P. Chen, Low Ag-Doped Titanium Dioxide Nanosheet Films with Outstanding Antimicrobial Property, Environ. Sci. Technol., 2010, 44(21), p 8270-8275

68. T.M. Chou, S.W. Chan, Y.J. Lin, P.K. Yang, C.C. Liu, Y.J. Lin, J.M. Wu, J.T. Lee, and Z.H. Lin, A Highly Efficient Au-MoS 
Nanocatalyst for Tunable Piezocatalytic and Photocatalytic Water Disinfection, Nano Energy, 2019, 57, p 14-21

69. F.L. Toma, L.M. Berger, D. Jacquet, D. Wicky, I. Villaluenga, Y.R. de Miguel, and J.S. Lindeløv, Comparative Study on the Photocatalytic Behaviour of Titanium Oxide Thermal Sprayed Coatings from Powders and Suspensions, Surf. Coat. Technol., 2009, 203(15), p 2150-2156

70. P. Puddu, S. Popa, G. Bolelli, P. Krieg, M.L. Gualtieri, L. Lusvarghi, A. Killinger, and R. Gadow, Suspension HVOF Spraying of $\mathrm{TiO}_{2}$ Using a Liquid-Fueled Torch, Surf. Coat. Technol., 2018, 349, p 677-694

71. M. Robotti, S. Dosta, C. Fernández-Rodríguez, M.J. HernándezRodríguez, I.G. Cano, E.P. Melián, and J.M. Guilemany, Photocatalytic Abatement of $\mathrm{NOx}$ by $\mathrm{C}-\mathrm{TiO}_{2} /$ Polymer Composite Coatings Obtained by Low Pressure Cold Gas Spraying, Appl. Surf. Sci., 2016, 362, p 274-280

72. L. Zhou, M. Cai, X. Zhang, N. Cui, G. Chen, and G.Y. Zou, InSitu Nitrogen-Doped Black $\mathrm{TiO}_{2}$ with Enhanced Visible-LightDriven Photocatalytic Inactivation of Microcystis aeruginosa Cells: Synthesization, Performance and Mechanism, Appl. Catal. B Environ., 2020, 272(119019), p 1-10

73. C. Zhang, U. Chaudhary, S. Das, A. Godavarty, and A. Agarwal, Effect of Porosity on Photocatalytic Activity of Plasma-Sprayed $\mathrm{TiO}_{2}$ Coating, J. Therm. Spray Technol., 2013, 22(7), p 11931200

74. H. Cui, J. Jiang, W. Gu, C. Sun, D. Wu, T. Yang, and G. Yang, Photocatalytic Inactivation Efficiency of Anatase $\mathrm{Nano}_{-} \mathrm{TiO}_{2}$ Sol on the $\mathrm{H}_{9} \mathrm{~N}_{2}$ Avian Influenza Virus, Photochem. Photobiol., 2010, 86(5), p 1135-1139

75. H. Chen, L. Zhao, Y. Xiang, Y. He, G.W. Song, X.T. Wang, and F. Liang, A novel $\mathrm{Zn}-\mathrm{TiO}_{2} / \mathrm{C} @ \mathrm{SiO}_{2}$ Nanoporous Material on Rice Husk for Photocatalytic Applications Under Visible Light, Desalin. Water Treat., 2016, 57(21), p 9660-9670

76. N.C. Birben, A. Tomruk, and M. Bekbolet, The role of Visible Light Active $\mathrm{TiO}_{2}$ Specimens on the Solar Photocatalytic Disinfection of E coli, Environ. Sci. Pollut. Res., 2017, 24(14), p 12618-12627

77. T. Koklic, S. Pintaric, I. Zdovc, M. Golob, P. Umek, A. Mehle, M. Dobeic, and J. Strancar, Photocatalytic Disinfection of Surfaces with Copper Doped $\mathrm{TiO}_{2}$ Nanotube Coatings Illuminated by Ceiling Mounted Fluorescent Light, PLoS ONE, 2018, 13(5), p 1-17

78. M. Feilizadeh, G. Mul, and M. Vossoughi, E. coli Inactivation by Visible Light Irradiation Using a $\mathrm{Fe}-\mathrm{Cd} / \mathrm{TiO}_{2}$ Photocatalyst: Statistical Analysis and Optimization of Operating Parameters, Appl. Catal. B Environ., 2015, 168, p 441-447

79. L.G. Bettini, M.V. Diamanti, M. Sansotera, M.P. Pedeferri, W. Navarrini, and P. Milani, Immobilized $\mathrm{TiO}_{2}$ Nanoparticles Produced by Flame Spray for Photocatalytic Water Remediation, J. Nanopart. Res., 2016, 18(8), p 238-247

80. M. Nararom, S. Thepa, J. Kongkiattikajorn, and R. Songprakorp, Disinfection of Water Containing Escherichia coli by Use of a Compound Parabolic Concentrator: Effect of Global Solar Radiation and Reactor Surface Treatment, Res. Chem. Intermed., 2015, 41(9), p 6543-6558

81. P. Ctibor, Z. Pala, V. Stengl, and R. Musalek, Photocatalytic Activity of Visible-Light-Active Iron-Doped Coatings Prepared by Plasma Spraying, Ceram. Int., 2014, 40(1), p 2365-2372

82. N. George, M. Mahon, and A. McDonald, Bactericidal Performance of Flame-Sprayed Nanostructured Titania-Copper Composite Coatings, J. Therm. Spray Technol., 2010, 19(5), p 10421053

83. M. Zhai, Y. Liu, J. Huang, W. Hou, S. Wu, B. Zhang, and H. Li, Fabrication of $\mathrm{TiO}_{2}-\mathrm{SrCO}_{3}$ Composite Coatings by Suspension Plasma Spraying: Microstructure and Enhanced Visible Light
Photocatalytic Performances, J. Therm. Spray Technol., 2020, 29(5), p 1172-1182

84. X. Chen, L. Liu, P.Y. Yu, and S.S. Mao, Increasing Solar Absorption for Photocatalysis with Black Hydrogenated Titanium Dioxide Nanocrystals, Science, 2011, 331(6018), p 746750

85. C.C. Chen, X.Z. Li, W.H. Ma, J.C. Zhao, H. Hidaka, and N. Serpone, Effect of Transition Metal Ions on the $\mathrm{TiO}_{2}$-Assisted Photodegradation of Dyes Under Visible Irradiation: A Probe for the Interfacial Electron Transfer Process and Reaction Mechanism, J. Phys. Chem. B, 2002, 106(2), p 318-324

86. S.E. Heo, H.W. Lim, D.K. Cho, I.J. Park, H. Kim, C.W. Lee, S.H. Ahn, and J.Y. Kim, Anomalous Potential Dependence of Conducting Property in Black Titania Nanotube Arrays for Electrocatalytic Chlorine Evolution, J. Catal., 2020, 381, p 462467

87. K. Carlson, C. Elliott, S. Walker, M. Misra, and S. Mohanty, An Effective, Point-of-Use Water Disinfection Device Using Immobilized Black $\mathrm{TiO}_{2}$ Nanotubes as an Electrocatalyst, $J$. Electrochem. Soc., 2016, 163(6), p H395-H401

88. L. Zhou, M. Cai, X. Zhang, N. Cui, G. Chen, and G.Y. Zou, InSitu Nitrogen-Doped Black $\mathrm{TiO}_{2}$ with Enhanced Visible-LightDriven Photocatalytic Inactivation of Microcystis aeruginosa Cells: Synthesization, Performance and Mechanism, Appl. Catal. B Environ., 2020, 272, p 119019-119028

89. Y. Xu, W. Wen, and J.M. Wu, Titania Nanowires Functionalized Polyester Fabrics with Enhanced Photocatalytic and Antibacterial Performances, J. Hazard. Mater., 2018, 343, p 285-297

90. R. Purbia, R. Borah, and S. Paria, Carbon-Doped Mesoporous Anatase $\mathrm{TiO}_{2}$ Multi-tubes Nanostructures for Highly Improved Visible Light Photocatalytic Activity, Inorg. Chem., 2017, 56(16), p 10107-10116

91. J. Yang, X. Zhang, B. Li, H. Liu, P. Sun, C. Wang, L. Wang, and Y. Liu, Photocatalytic Activities of Heterostructured $\mathrm{TiO}_{2-}$ Graphene Porous Microspheres Prepared by Ultrasonic Spray Pyrolysis, J. Alloys Compd., 2014, 584, p 180-184

92. B.W. Robinson, C.J. Tighe, R.I. Gruar, A. Mills, I.P. Parkin, A.K. Tabecki, H.L.D.V. Lovelock, and J.A. Darr, Suspension Plasma Sprayed Coatings Using Dilute Hydrothermally Produced Titania Feedstocks for Photocatalytic Applications, $J$. Mater. Chem. A, 2015, 3(24), p 12680-12689

93. O. Sugiyama, M. Okuya, and S. Kaneko, Photocatalytic Ability of $\mathrm{TiO}_{2}$ Porous Film Prepared by Modified Spray Pyrolysis Deposition Technique, J. Ceram. Soc. Jpn., 2009, 117(1362), p 203-207

94. R. Jbeli, A. Boulthachem, F. Saadallah, S. Alleg, M. Amlouk, and H. Ezzaouia, Synthesis and Physical Properties of Fe Doped $\mathrm{La}_{2} \mathrm{O}_{3}$ Thin Films Grown by Spray Pyrolysis for Photocatalytic Applications, Mater. Res. Exp., 2019, 6(6), p 1-10

95. L. Zhang, S. Yu, K. Wang, J. Zhang, and J. Fang, A Cost- and Time-saving Strategy of Spraying $\mathrm{TiO}_{2}$ Self-Cleaning Coatings in Tubular Substrates by Air Cold Plasma, Chem. Phys. Lett., 2017, 687, p 205-208

96. Y.F. Lin, K.L. Tung, Y.S. Tzeng, J.H. Chen, and K.S. Chang, Rapid Atmospheric Plasma Spray Coating Preparation and Photocatalytic Activity of Macroporous Titania Nanocrystalline Membranes, J. Membr. Sci., 2012, 389, p 83-90

97. M.C. Bordes, M. Vicent, R. Moreno, J. Garcia-Montano, A. Serra, and E. Sanchez, Application of Plasma-Sprayed $\mathrm{TiO}_{2}$ Coatings for Industrial (Tannery) Wastewater Treatment, Ceram. Int., 2015, 41(10), p 14468-14474

98. T.H. Kim, S.W. Lee, H. Chen, and H.Y. Cho, Photocatalytic Characterization of Plasma Sprayed $\mathrm{TiO}_{2}$ Coating in Environmental Engineering Application, Mater. Sci. Forum, 2006, 510-511, p 70-73 
99. J.W. Macfarlane, H.F. Jenkinson, and T.B. Scott, Sterilization of Microorganisms on Jet Spray Formed Titanium Dioxide Surfaces, Appl. Catal. B Environ., 2011, 106(1-2), p 181-185

100. J. Huang, Y. Gong, Y. Liu, X. Suo, and H. Li, Developing Titania-Hydroxyapatite-Reduced Graphene Oxide Nanocomposite Coatings by Liquid Flame Spray Deposition for Photocatalytic Applications, J. Eur. Ceram. Soc., 2017, 37(12), p 3705-3711

101. M.P. Reddy, H.H. Phil, and M. Subrahmanyam, Photocatalytic Disinfection of Escherichia coli over Titanium(IV) Oxide Supported on H Beta Zeolite, Catal. Lett., 2008, 123, p 56-64

102. M. Giannouri, T. Kalampaliki, N. Todorova, T. Giannakopoulou, N. Boukos, D. Petrakis, T. Vaimakis, and C. Trapalis, One-Step Synthesis of $\mathrm{TiO}_{2} /$ Perlite Composites by Flame Spray Pyrolysis and Their Photocatalytic Behavior, Int. J. Photoenergy, 2013, 2013, p 729460-729467

103. A. Nakajima, K. Takakuwa, Y. Kameshima, M. Hagiwara, S. Sato, Y. Yamamoto, N. Yoshida, T. Watanabe, and K. Okada, Preparation and Properties of Titania-Apatite Hybrid Films, $J$. Photochem. Photobiol. A Chem., 2006, 177(1), p $94-99$

104. Y. Liu, J. Huang, S. Ding, Y. Liu, J. Yuan, and H. Li, Deposition, Characterization, and Enhanced Adherence of Escherichia coli Bacteria on Flame-Sprayed Photocatalytic TitaniaHydroxyapatite Coatings, J. Therm. Spray Technol., 2013, 22(6), p 1053-1062

105. J. Huang, Y. Liu, Y. Liu, and H. Li, Hydroxyapatite Nucleated and Grown on Nano Titania Particles Enhances Recruitment of Escherichia coli for Subsequent Photocatalytic Elimination, Mater. Chem. Phys., 2015, 151, p 364-371

106. Y. Yamaguchi, S. Usuki, Y. Kanai, K. Yamatoya, N. Suzuki, K.I. Katsumata, C. Terashima, T. Suzuki, A. Fujishima, H. Sakai, A. Kudo, and K. Nakata, Selective Inactivation of Bacteriophage in the Presence of Bacteria by Use of Ground RhDoped $\mathrm{SrTiO}_{3}$ Photocatalyst and Visible Light, ACS Appl. Mater. Interfaces, 2017, 9(37), p 31393-31400

107. K. Ren, Y. Liu, X. He, and H. Li, Suspension Plasma Spray Fabrication of Nanocrystalline Titania Hollow Microspheres for Photocatalytic Applications, J. Therm. Spray Technol., 2015, 24(7), p 1213-1220

108. X. He, K. Ren, Y. Liu, J. Huang, and H. Li, Hollow PlasmaSprayed Spherical Nanostructured Titania Feedstock for Photocatalytic Applications, J. Therm. Spray Technol., 2018, 27(8), p 1532-1541

109. S. Giannakis, S. Liu, A. Carratala, S. Rtimi, M.T. Amiri, M. Bensimon, and C. Pulgarin, Iron Oxide-Mediated Semiconductor Photocatalysis vs. Heterogeneous Photo-Fenton Treatment of Viruses in Wastewater. Impact of the Oxide Particle Size, $J$. Hazard. Mater., 2017, 339, p 223-231

110. W.J. Ma, Y.C. Ding, M.J. Zhang, S.T. Gao, Y.S. Li, C.B. Huang, and G.D. Fu, Nature-Inspired Chemistry Toward Hierarchical Superhydrophobic, Antibacterial and Biocompatible Nanofibrous Membranes for Effective UV-Shielding, SelfCleaning and Oil-Water Separation, J. Hazard. Mater., 2020, 384, p 121476-121488

111. J. Yuan, Q. Zhan, Q. Lei, S. Ding, and H. Li, Fabrication and Characterization of Hybrid Micro/Nano-Structured Hydrophilic Titania Coatings Deposited by Suspension Flame Spraying, Appl. Surf. Sci., 2012, 258(17), p 6672-6678

112. H.Y. He, Photoinduced Superhydrophilicity and High Photocatalytic Activity of ZnO-Reduced Graphene Oxide Nanocomposite Films for Self-Cleaning Applications, Mater. Sci. Semicond. Proc., 2015, 31, p 200-208

113. Y. Won, K. Schwartzenberg, and K.A. Gray, $\mathrm{TiO}_{2}$-Based Transparent Coatings Create Self-Cleaning Surfaces, Chemosphere, 2018, 208, p 899-906
114. H. Teisala, M. Tuominen, M. Aromaa, J.M. Makela, M. Stepien, J.J. Saarinen, M. Toivakka, and J. Kuusipalo, Development of Superhydrophobic Coating on Paperboard Surface Using the Liquid Flame Spray, Surf. Coat. Technol., 2010, 205(2), p 436445

115. L. Valenzuela, Antimicrobial Surfaces with Self-Cleaning Properties Functionalized by Photocatalytic $\mathrm{ZnO}$ Electrosprayed Coatings, J. Hazard. Mater., 2019, 369, p 665-673

116. H.F. Huang, Y.Q. An, X. Hu, D. Wu, H.W. Cao, X. Zhang, J.H. Qiao, and H.T. Liu, A Plasma Sprayed Superhydrophobic Coating Prepared with $\mathrm{Al} @ \mathrm{WO}_{3}$ Core-Shell Powder and Photocatalytic Degradation Performance, Surf. Coat. Technol., 2019, 369, p 105-115

117. M.F. Blanca Jalvoa, A. Bahamonde, and R. Rosal, Antimicrobial and Antibiofilm Efficacy of Self-Cleaning Surfaces Functionalized by $\mathrm{TiO}_{2}$ Photocatalytic Nanoparticles Against Staphylococcus aureus and Pseudomonas putida, J. Hazard. Mater., 2017, 340, p 160-170

118. B. Jeffery, M. Peppler, R.S. Lima, and A. McDonald, Bactericidal Effects of HVOF-Sprayed Nanostructured $\mathrm{TiO}_{2}$ on Pseudomonas aeruginosa, J. Therm. Spray Technol., 2010, 19, p 344349

119. Y. Kikuchi, K. Sunada, T. Iyoda, K. Hashimoto, and A. Fujishima, Photocatalytic Bactericidal Effect of $\mathrm{TiO}_{2}$ Thin Films: Dynamic View of the Active Oxygen Species Responsible for the Effect, J. Photochem. Photobiol. A Chem., 1997, 106, p 51-56

120. J. Rodríguez, F. Paraguay-Delgado, A. López, J. Alarcón, and W. Estrada, Synthesis and Characterization of $\mathrm{ZnO}$ Nanorod Films for Photocatalytic Disinfection of Contaminated Water, Thin Solid Films, 2010, 519, p 729-735

121. K. Chen, Y. Liu, Y. Fu, J. Huang, X. Feng, J. Wang, M. Zhai, R. Lupoi, S. Yin, and H. Li, Loading of $\mathrm{Zn} / \mathrm{ZnO}$ Particles in the Precursor Feedstock Affects the Characteristics of Liquid Plasma Sprayed Nano-ZnO Coatings for Photocatalytic Applications, Nanotechnology, 2020, 31(18), p 185301

122. S. Heinonen, M. Kannisto, J.P. Nikkanen, E. Huttunen-Saarivirta, M. Karp, and E. Levanen, Photocatalytic and Antibacterial Properties of $\mathrm{ZnO}$ Films with Different Surface Topographies on Stainless Steel Substrate, Thin Solid Films, 2016, 616, p 842-849

123. J. Rodríguez Rodriguez, F. Paraguay-Delgado, A. Lopez, J. Alarcon, and W. Estrada, Synthesis and Characterization of $\mathrm{ZnO}$ Nanorod Films for Photocatalytic Disinfection of Contaminated Water, Thin Solid Films, 2010, 519(2), p 729-735

124. P. Venkata, L. Reddy, B. Kavith, P. Anil, K. Reddy, and K.H. $\mathrm{Kim}, \mathrm{TiO}_{2}$-Based Photocatalytic Disinfection of Microbes in Aqueous Media: A Review, Environ. Res., 2017, 154, p 296-303

125. X. Zheng, Z.P. Shen, C. Cheng, L. Shi, R. Cheng, and J. Dong, Electrospinning $\mathrm{Cu}-\mathrm{TiO}_{2}$ Nanofibers Used for Photocatalytic Disinfection of Bacteriophage f2: Preparation, Optimization and Characterization, RSC Adv., 2017, 7(82), p 52172-52179

126. X. Zheng, Z.P. Shen, C. Cheng, L. Shi, R. Cheng, and D.H. Yuan, Photocatalytic Disinfection Performance in Virus and Virus/Bacteria System by $\mathrm{Cu}-\mathrm{TiO}_{2}$ Nanofibers Under Visible Light, Environ. Pollut., 2018, 237, p 452-459

127. G.S. Song, C.Z. Luo, Q. Fu, and C.X. Pan, Hydrothermal Synthesis of the Novel Rutile-Mixed Anatase $\mathrm{TiO}_{2}$ Nanosheets with Dominant 001 Facets for High Photocatalytic Activity, RSC $A d v ., 2016,6(87)$, p 84035-84041

128. H. Ishiguro, R. Nakano, Y. Yao, J. Kajioka, A. Fujishima, K. Sunada, M. Minoshima, K. Hashimoto, and Y. Kubota, Photocatalytic Inactivation of Bacteriophages by $\mathrm{TiO}_{2}$-Coated Glass Plates Under Low-Intensity, Long-Wavelength UV Irradiation, Photochem. Photobiol. Sci., 2011, 10(11), p 1825-1829 
129. I.B. Ditta, A. Steele, C. Liptrot, J. Tobin, H. Tyler, H.M. Yates, D.W. Sheel, and H.A. Foster, Photocatalytic Antimicrobial Activity of Thin Surface Films of $\mathrm{TiO}_{2}, \mathrm{CuO}$ and $\mathrm{TiO}_{2} / \mathrm{CuO}$ Dual Layers on Escherichia coli and Bacteriophage $\mathrm{T}_{4}$, Appl. Microbiol. Biotechnol., 2008, 79(1), p 127-133

130. M.V. Liga, E.L. Bryant, V.L. Colvin, and Q. Li, Virus Inactivation by Silver Doped Titanium Dioxide Nanoparticles for Drinking Water Treatment, Water Res., 2011, 45(2), p 535-544

131. C. Zhang, Y. Li, W. Zhang, P. Wang, and C. Wang, Metal-Free Virucidal Effects Induced by $\mathrm{g}_{-} \mathrm{C}_{3} \mathrm{~N}_{4}$ Under Visible Light Irradiation: Statistical Analysis and Parameter Optimization, Chemosphere, 2018, 195, p 551-558

132. I. Horovitz, D. Avisar, E. Luster, L. Lozzi, T. Luxbacher, and H. Mamane, $\mathrm{MS}_{2}$ Bacteriophage Inactivation Using a $\mathrm{N}$-doped $\mathrm{TiO}_{2}$-Coated Photocatalytic Membrane Reactor: Influence of Water-Quality Parameters, Chem. Eng. J., 2018, 354, p 9951006
133. J. Zhang, M. Yuan, X. Liu, X. Wang, S. Liu, B. Han, B. Liu, and H. Shi, Copper Modified $\mathrm{Ti}^{3+}$ Self-Doped $\mathrm{TiO}_{2}$ Photocatalyst for Highly Efficient Photodisinfection of Five agricultural Pathogenic Fungus, Chem. Eng. J., 2020, 387, p 124171-124179

134. G.S. El-Sayyad, M. Abd Elkodous, A.M. El-Khawaga, M.A. Elsayed, A.I. El-Batal, and M. Gobara, Merits of Photocatalytic and Antimicrobial Applications of Gamma-Irradiated $\mathrm{Co}_{\mathrm{x}} \mathrm{Ni}_{1-\text { - }}$ ${ }_{x} \mathrm{Fe}_{2} \mathrm{O}_{4} / \mathrm{SiO}_{2} / \mathrm{TiO}_{2}, \quad \mathrm{x}=0.9$ Nanocomposite for Pyridine Removal and Pathogenic Bacteria/Fungi Disinfection: Implication for Wastewater Treatment, RSC Adv., 2020, 10(9), p 52415259

Publisher's Note Springer Nature remains neutral with regard to jurisdictional claims in published maps and institutional affiliations. 